\title{
The design of railway overhead line equipment mast foundations
}

\section{William Powrie FREng}

Professor of Geotechnical Engineering, School of Engineering,

Faculty of Engineering and Physical Sciences, University of Southampton,

Southampton, UK

David J. Richards BEng, MSt, PhD, CEng, MICE

Professor of Ground Engineering, School of Engineering, Faculty of

Engineering and Physical Sciences, University of Southampton,

Southampton, UK (corresponding author: djr@soton.ac.uk)
Vaneshen K. S. Mootoosamy BEng (Hons), MSC, GMICE, MBCS IP Programme Engineering Manager B\&C, Network Rail, UK

Railway electrification offers significant benefits in terms of decarbonisation at the point of use and reduced traction costs. However, to realise these benefits, the fixed infrastructure must be provided at an affordable cost. Recent schemes in the UK have seen the cost of railway electrification soar: one of a number of reasons for this has been the substantial increase in mast foundation pile lengths compared with historic practice. The paper explores this through a comparative review of traditional and modern pile design methods. In addressing the ultimate limit state, the various approaches are shown to give broadly consistent results in terms of pile length. However, increased pile lengths will be calculated if three-dimensional effects are not allowed for in limit equilibrium (ultimate limit state) calculations, or if a serviceability limit state calculation is carried out using unrealistically low soil stiffness. The results of the comparative analyses should give designers the confidence to use the traditional empirical approach, or a limit equilibrium calculation without the need for an explicit serviceability limit state check (as permitted by Eurocode 7) using potentially inappropriate soil stiffness parameters.

\section{Notation}

the smaller of the International Union of Railways Office for Research \&t Experiments (ORE) dimensions, $e$ and $b$ ORE dimension of the foundation block viewed on plan (perpendicular to overturning force)

$c_{\mathrm{u}} \quad$ undrained shear strength

$D \quad$ effective foundation length (Figure 3)

$d$ pile diameter

$e \quad$ height of action of lateral load above effective top of foundation (Figure 4, limit equilibrium analyses (LEA)) ORE dimension of the foundation viewed on plan (parallel to overturning force) horizontal force (Figure 2) ORE height above top of foundation at which equivalent lateral load is applied equivalent lateral load (Figure 4, LEA) ORE ineffective depth ORE total embedded depth distance from the track to the foundation ORE terrain factor in situ pressure coefficient passive pressure coefficient width of the foundation total embedded depth of foundation ORE moment limit at ground level cross-track moment at ground level ORE ultimate moment of resistance at ground level (daNm) uncorrected moment limit (ORE)
$N_{\mathrm{q}} \quad$ bearing capacity factor

$\mathrm{Nr} \quad$ ORE total vertical load on foundation

$p_{\mathrm{u}} \quad$ limiting lateral load per unit pile depth

$T \quad$ ORE equivalent lateral load (daN)

$u \quad$ pore water pressure

$W \quad$ weight of cantilever boom

$W_{\mathrm{F}} \quad$ weight of foundation

$W_{\mathrm{M}} \quad$ weight of mast

$w \quad$ weight of cantilever boom and overhead line equipment acting at centroid (Figure 2)

$x \quad$ eccentricity from centroid of foundation

$y \quad$ height above ground level that horizontal force is acting $z \quad$ depth

$z_{\mathrm{p}} \quad$ depth from effective top of foundation to pivot point

$\beta \quad$ embankment slope angle

$\gamma \quad$ soil unit weight

$\gamma^{*} \quad$ effective soil unit weight

$\gamma_{\mathrm{w}} \quad$ unit weight of water

$\Delta \quad$ ORE specific weight of the soil $\left(\mathrm{kg} / \mathrm{m}^{3}\right)$

$\delta \quad$ soil/pile friction angle

$\theta \quad$ rotation in principal stress direction

$\sigma_{\mathrm{h}}^{\prime} \quad$ horizontal effective stress

$\phi^{\prime} \quad$ angle of shearing resistance

\section{Introduction}

Railway electrification offers benefits for both the environment (zero carbon dioxide $\left(\mathrm{CO}_{2}\right)$ and particulate emissions at the point of use) and traction operation (reduced complexity and cost), but requires investment in fixed infrastructure. If this 
can be provided economically, the life-cycle benefits of electrification should outweigh the costs, especially on an intensively used railway. However, recent experience with the UK Great Western mainline electrification project (GWEP) has not been encouraging, with projected costs rising from $£ 900$ million in 2013 to $£ 2.8$ billion in 2016 (NAO, 2016). Costs of this magnitude make the economic argument for electrification challenging, but in the case of GWEP, political and contractual commitments (particularly to a new fleet of electric trains) had already been made. The specification of the trains was changed from electric-only to bi-mode (with diesel engines capable of powering the trains for main line running) when it became clear that electrification would be delayed - possibly indefinitely on parts of the route (e.g. Bristol Temple Meads and west of Cardiff).

The design and installation of the overhead line masts, and in particular their foundations, seems to have been a key factor in the GWEP cost over-run (RIA, 2019). A high-output piling system (HOPS) factory train was specified and built on the basis of previous experience with UK main line electrification, which suggested a maximum pile length of $5.5 \mathrm{~m}$. Unfortunately, the simultaneous development of a revised approach to pile foundation design (Krechowiecki-Shaw and Alobaidi, 2015) led to an apparently significant increase in design foundation depths. The development of both the HOPS and the revised foundation design process occurred in advance of the specification of the overhead line equipment (OLE) itself. In the event, the more massive 'Series 1' superstructure added to the problem by increasing the loads (compared with previous norms) that the foundations were required to carry.
While all of these changes were individually well intentioned, aiming variously to

- give a design framework clearly founded on modern soil mechanics principles and unequivocally compliant with Eurocodes

minimise the number of track possessions needed for installation

- generally de-risk the installation process

- reduce the potential for failure in service, and the associated disruption

their combined effect on the credibility and affordability of the UK electrification programme has been catastrophic (e.g. curtailment of GWEP at Cardiff, and cancellation of the Midland Main Line electrification scheme). A common thread has been a loss of awareness and/or confidence in the knowledge gained through previous experience, particularly in the design of OLE mast foundations.

This paper

- summarises the traditional and revised approaches to OLE pile foundation design

discusses their philosophical differences

- compares the results of calculations for OLE structural and foundation loads typical of the GWEP 'Series 1' designs

discusses the implications of the foundation design approach adopted for future railway over-line electrification.

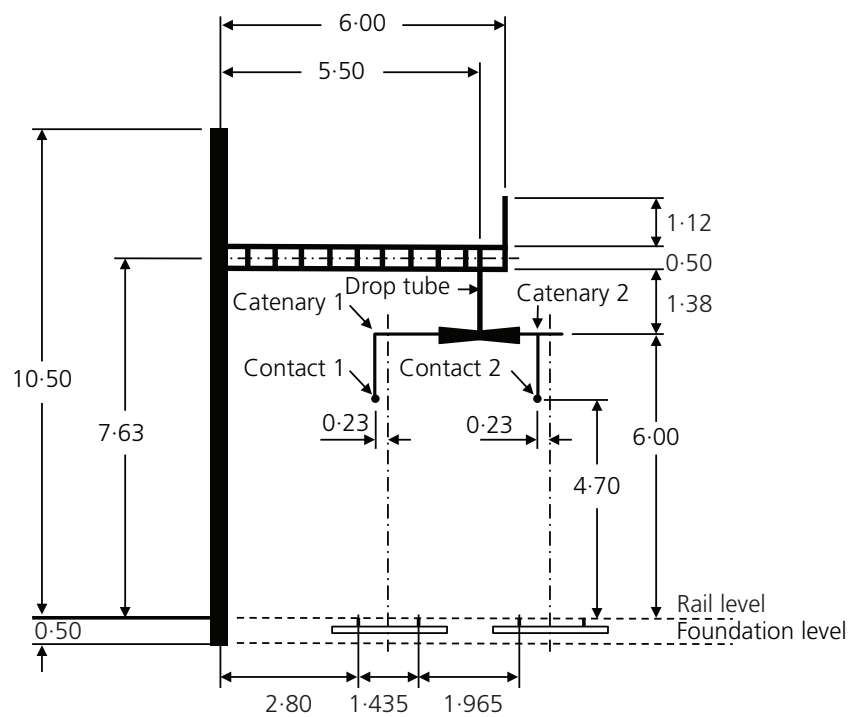

(a)

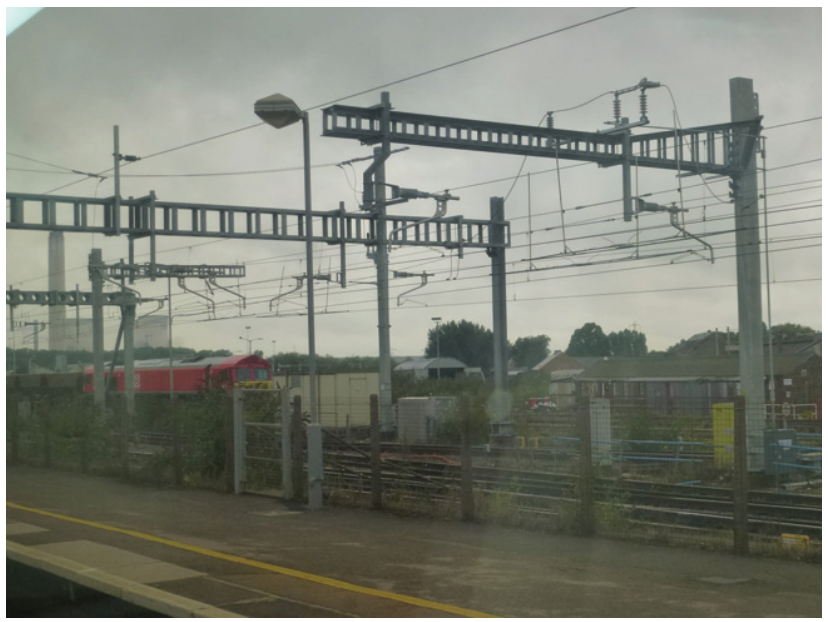

(b)

Figure 1. Standard 'Series 1' TTC OLE support structure: (a) line drawing (dimensions in m); (b) photograph 


\section{Background}

This section summarises the loads associated with the GWEP OLE masts, and the fundamental basis and key attributes of the various methods for calculating foundation pile length.

\subsection{Loads applied to OLE mast foundations}

Three standard types of new 'Series 1' cantilever OLE support structure were developed; the single-track cantilever (STC), the twin-track (also referred to as two-track) cantilever (TTC) and the extra-large TTC (XL-TTC). The regular TTC, designed to support electrification equipment over two adjacent tracks, is shown in Figures 1(a) and 1(b).

The principal loads on an OLE mast foundation are

the weight of the mast, $W_{\mathrm{M}}$, and of the foundation itself, $W_{\mathrm{F}}$ acting vertically downward through the centroid of the foundation

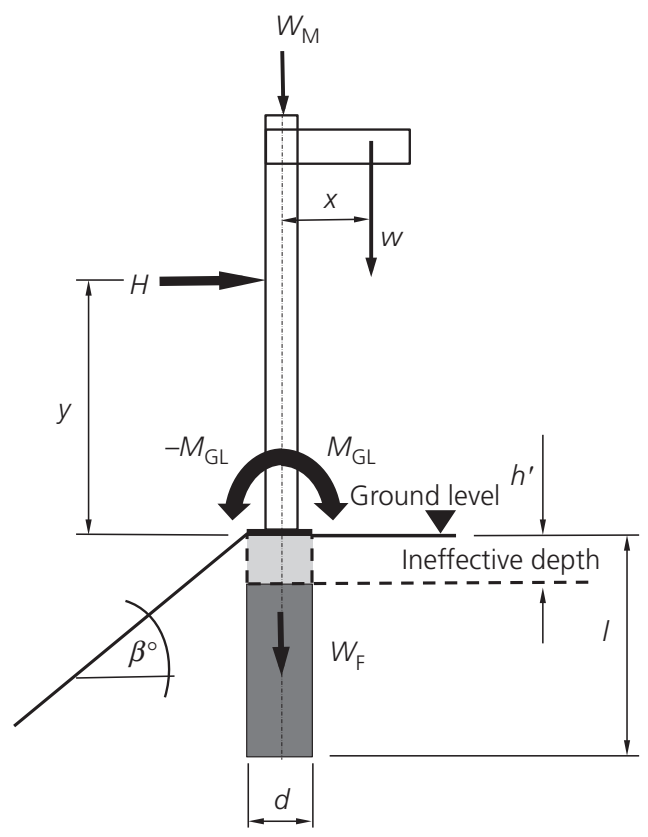

Figure 2. Idealised foundation loads the weight of the cantilever boom and the OLE it supports (plus snow/ice loading as appropriate), $w$, acting downward at an eccentricity $x$ from the centroid of the foundation

- a horizontal load, $H$, representing cross-track wind and potentially an in-plane component of wire tension on curved track, acting at a height $y$ above ground level.

At the top of the foundation (assumed here to be at ground level), the generalised forces are statically equivalent to

a vertical force $\left(W_{\mathrm{M}}+W_{\mathrm{F}}+w\right)$

a horizontal force, $H$

a moment of either $(H y+w x)$ towards the track, or $(H y-w x)$ away from the track, depending on the net direction of $H$.

The key design load for an OLE foundation is the cross-track moment at ground level, $M_{\mathrm{GL}}=(H y+w x)$ towards the track or $M_{\mathrm{GL}}=(H y-w x)$ away from the track. The larger moment, with $H$ acting towards the track and increasing the moment due to $w$ - which may or may not be the worst case depending on the slope of the terrain - is shown in Figure 2. This paper focuses on $M_{\mathrm{GL}}$; it does not address the vertical capacity check that would also need to be carried out for design according to standard geotechnical engineering principles.

For simplicity, it is assumed that there is no upstand to the foundation and, if the pile is installed in an embankment, the downslope commences at the side of the pile further from the track, so there is no loss of embedment. The total embedded length of the foundation is $l$ metres, of which the uppermost $h^{\prime}$ metres may be considered to be ineffective, owing, for example, to disturbance during pile installation.

The most onerous characteristic loads, expressed as moment at ground level $\left(M_{\mathrm{GL}}\right)$ were calculated for the three standard types of Series 1 OLE structure by Buro Happold (2015a, $2015 b, 2015 c$ ) and are summarised in Table 1. These define the range of interest for comparative calculations for the foundation analysis methods. The structure must fulfil serviceability limits on variable-load deflection at the wire height under a 1 in 3 year wind load but not under a 1 in 50 wind load, when

Table 1. Characteristic (design or service) worst-case combinations of vertical and across-track loads (horizontal and moment) associated with three types of Series 1 OLE structure (Buro Happold, 2015a, 2015b, 2015c)

\begin{tabular}{|c|c|c|c|c|}
\hline Structure type & Loading direction & Permanent & Variable (3 year wind return period) & Variable ( 50 year wind return period) \\
\hline \multirow[t]{3}{*}{ STC } & Vertical: kN & $10 \cdot 47$ & - & - \\
\hline & Horizontal: kN & $1 \cdot 16$ & 9.051 & $13 \cdot 260$ \\
\hline & Moment: kNm & $13 \cdot 69$ & $55 \cdot 656$ & $80 \cdot 680$ \\
\hline \multirow[t]{3}{*}{ TTC } & Vertical: kN & $26 \cdot 97$ & - & - \\
\hline & Horizontal: kN & $2 \cdot 32$ & $13 \cdot 433$ & $19 \cdot 900$ \\
\hline & Moment: kNm & $63 \cdot 61$ & $85 \cdot 203$ & $125 \cdot 350$ \\
\hline \multirow[t]{3}{*}{ XL-TTC } & Vertical: kN & $47 \cdot 60$ & - & - \\
\hline & Horizontal: kN & - & $21 \cdot 274$ & $29 \cdot 400$ \\
\hline & Moment: kNm & $180 \cdot 70$ & $171 \cdot 608$ & $235 \cdot 800$ \\
\hline
\end{tabular}


the structure must fulfil only the ultimate limit state (ULS) criterion.

The symbols shown in Figure 2 mainly follow Fleming et al. (1994, 2009). Other authors use different symbols and sometimes different terms. In the description and discussion of each method that follow, the original symbols are retained to facilitate reference back to the source documents. Later, where the results of different methods are compared, the Fleming et al. (1994, 2009) notation and symbols are generally adopted. A full list of symbols is provided in Appendix 1.

\subsection{Empirical analysis: the International Union of Railways-Office for Research and Experiments (UIC-ORE)}

The International Union of Railways - Office for Research and Experiments (UIC-ORE) method (UIC-ORE, 1957) is based on a series of formulae derived from the results of reducedscale model tests on square, rectangular and circular section foundations in dry sand carried out and reported by Ramelot and van Deperre (1950) and subsequently modified following a series of full-scale tests. It is based purely on observation, and does not explicitly distinguish between drained and undrained conditions. The relevant formulae are as follows.

1. $M_{\mathrm{B}}=(M r)_{\mathrm{p}}(1-E p)$

where

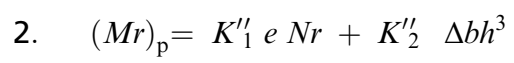

3. $K_{1}^{\prime \prime}=\left(0.5136-\frac{0 \cdot 175}{0.54+(b / e)}\right)$

4. $K_{2}^{\prime \prime}=\left\{2 \cdot 8-\frac{96 \cdot 5}{68 \cdot 5+3 \cdot 375[N r /(10 \Delta b e a)]^{3}}\right\}$

$$
\times[1+0 \cdot 45(e / b)]
$$

$M_{\mathrm{B}}$ is the moment limit at ground level; $h$ is the total embedded depth of the foundation block (interpreted as the total; i.e. including any ineffective or unconsolidated depth, $\left.h^{\prime}\right) ; e$ is the dimension of the block, viewed on plan, parallel to the overturning force; $b$ is the dimension of the block, viewed on plan, perpendicular to the overturning force; $a$ is the smaller of the two dimensions, $e$ and $b ; N r$ is the total vertical load (the weight of the block, the mast and equipment); $\Delta$ is the specific weight of the soil, 'specific weight' being the term used in the UIC-ORE (1957) report. The units are given as $\mathrm{kg} / \mathrm{m}^{3}$; it seems that this is an approximation for decaNewtons per cubic metre $\left(\mathrm{daN} / \mathrm{m}^{3}\right)$, because (although it is not obvious in the UIC-ORE report) the forces are assumed to be in decaNewton (daN) and moments in decaNewton-metres (daNm).

$(1-E p)$ is a correction factor to allow for a depth $h^{\prime}$ of replaced, unconsolidated or otherwise ineffective soil at the surface of the foundation, and is calculated using the expression

5. $(1-E p)=3.44\left[1+\left(\frac{h^{\prime}}{h}\right)^{3}\right]-2.44 \times \sqrt{\left[1+\left(\frac{h^{\prime}}{h}\right)^{2}\right]^{3}}$

If the foundation is a cylindrical block of diameter $d$, $e=b=a=0 \cdot 8 d$. Although $M_{\mathrm{B}}$ is described as a 'moment limit', the UIC-ORE (1957) report states that the foundation movements were small and remained stable at this load.

The full-scale tests carried out under the auspices of the ORE investigated the effect of three different configurations of ground (in a cutting, on the level and on an embankment) and different degrees of support from the track (close to the track and further from the track, with pull towards the track and pull in the direction away from the track). These led to a final equation of the form

6. $M_{\text {ult }}=27.45 K\left(M_{\mathrm{B}}\right)^{2 / 3}$

where $M_{\text {ult }}$ in decaNewton-metres $(\mathrm{daNm})$ is the ultimate moment of resistance of the foundation, measured at ground level. (The original UIC-ORE report expresses $M_{\text {ult }}$ as $(T H)_{\text {limit }}$, where $T$ is the equivalent lateral load in decaNewton $(\mathrm{daN})$ and $H(\mathrm{~m})$ is the height above the top of the foundation at which it acts). $K$ is a numerical multiplier (' $K$ factor'), which accounts for the slope of the ground and the degree of support from the track; values are given in Table 2, where $i$ is the distance from the track to the foundation (it is not clear how this is measured, e.g. from the centreline, or from the nearest rail). $M_{\mathrm{B}}$ is in daNm. Because the two sides of Equation 6 are dimensionally inconsistent, the constant $27 \cdot 45$ has units of $(\mathrm{daNm})^{1 / 3}$. With $T$ in $\mathrm{kN}$ and $H$ in metres $\left(M_{\mathrm{ult}}\right.$ and $M_{\mathrm{B}}$ in $\left.\mathrm{kNm}\right)$, the constant becomes numerically equal to $5 \cdot 194$ and has units of $(\mathrm{kNm})^{1 / 3}$.

The allowable value of moment at ground level, $M_{\mathrm{GL}}$, is obtained by dividing the value of $M_{\text {ult }}$ from Equation 6 by a factor of 3 . This is equivalent to applying a partial factor to the ultimate resistance of the foundation, expressed as an overturning moment. In addition to the terrain ' $K$ factor', foundation lengths may be further modified according to a series of corrections that account for the proximity to the crest of a slope and/or a drainage or cable trench (filled or unfilled). These corrections may either increase or reduce the foundation lengths, and are influenced by the shape of the foundation cross-section on plan (parallelepiped or circular). Circular foundations are slightly more sensitive to topographical features, as summarised in Appendix 2. 
Table 2. ORE $K$ factors (UIC-ORE, 1957)

\begin{tabular}{lccc} 
& \multicolumn{3}{c}{ Direction of pull } \\
\cline { 2 - 4 } $\begin{array}{l}\text { Terrain } \\
\text { (topography) }\end{array}$ & $\begin{array}{c}\text { Away from } \\
\text { track }\end{array}$ & \multicolumn{2}{c}{ Towards track } \\
\cline { 2 - 4 } Embankment & 0.85 & 0.95 & $1>2 \mathrm{~m}$ \\
Level & 1 & 1.3 & 2 \\
Cutting & 1.5 & 1.8 & 2 \\
\end{tabular}

\subsection{OLE Master Index (OLEMI)}

Inspection of Equations 2 and 4 shows that neglecting the vertical loads $W_{\mathrm{M}}, W_{\mathrm{F}}$ and $w(N r$ in Equations 2 and 4$)$ will lead to a conservative design. The simplification resulting from not having to consider the effect of the foundation weight enables generic look-up charts or tables to be developed. Neglecting the weight of the foundation also removes any distinction in the calculation between foundations made of steel and foundations made of concrete. Thus a relationship between total foundation depth, $h$, and factored ultimate moment resistance, $M_{\mathrm{ult}} / 3$, may be developed that is a function of only the foundation cross-sectional dimensions (e.g. the diameter, $d$ ), the effective soil unit weight, $\gamma^{*}(=\gamma-(\mathrm{d} u / \mathrm{d} z))$, and the disturbed or unconsolidated soil depth, $h^{\prime} .(\mathrm{d} u / \mathrm{d} z$ is the rate of increase in pore water pressure, $u$, with depth $z$. In hydrostatic conditions, $\mathrm{d} u / \mathrm{d} z=\gamma_{\mathrm{w}}$ and $\gamma^{*}=\left(\gamma-\gamma_{\mathrm{w}}\right)$.)

This is the basis of the OLEMI method of design, a modified and more conservative version of the ORE approach in which the beneficial effect of the weight of the foundation and OLE structure is neglected (Mootoosamy et al., 2015). For the Series 1 loads (Table 1), OLEMI gives foundations that are typically 10 to $20 \%$ longer than those determined using the original ORE method. This paper reports pile lengths derived using the OLEMI methodology.

In a further development, the UK Master Series (Network Rail, 2015a) provides 'strength depth' tables for allocating concrete and tubular steel pile foundations based on an OLEMI design using an ineffective near-surface depth $h^{\prime}=0 \cdot 3 \mathrm{~m}$, a terrain factor $K=1 \cdot 3$ or $K=1$ (i.e. level ground with acrosstrack or away-from-track loading, respectively) and a soil effective unit weight $\gamma^{*}=15 \mathrm{kN} / \mathrm{m}^{3}$. Appendix 2 summarises the factors and additional corrections that must be applied to extend the foundation 'strength depth' tables to foundation allocation for different foundation types, terrain conditions and loading directions.

\subsection{Range of applicability of ORE and OLEMI methods}

The ORE method is empirical, in that Equation 6 was determined directly from experimental results in a range of terrain types, rather than by considering either a limiting or an in-service ('working') stress distribution - something that is difficult to address in sloping terrain such as an embankment.
The authority of the method derives from the international collaborative research that went into developing it, together with the fact that it has been used extensively and successfully by railway administrations in Europe for decades - including on Network Rail and High-Speed 1 (AMEC SPIE Rail, 2000).

Given the empirical nature of the method, it is important that it should not be used outside its current evidence base. In particular, the tests described in the original UIC-ORE (1957) report

were for concrete foundations up to $3 \mathrm{~m}$ long

- involved design moments at ground level of up to $130 \mathrm{kNm}$ away from the track and $170 \mathrm{kNm}$ towards the track for flat terrain $(K=1)$, and design moments at ground level of up to $190 \mathrm{kNm}$ away from the track and $230 \mathrm{kNm}$ towards the track in a cutting $(K=1 \cdot 8)$.

The report also states that the unconsolidated depth, $h^{\prime}$, would not normally be expected to exceed $0.5 \mathrm{~m}$; and cautions that the full effect of the foundation weight, although appearing in the factor $K_{2}^{\prime}$ defined in Equation 4, is not completely captured by the equations.

A review of Network Rail's experience of the OLEMI method (Mootoosamy et al., 2015) highlighted its use in the design of a range of foundations since 1984, with no reported instances of subsequent associated failure (collapse or loss of serviceability). Electrification of the East Coast Main Line between 1986 and 1992 represents the most extensive use of ORE-based foundation design in the UK, in which the Master Series 'strength depth' tables were applied to both concrete and $610 \mathrm{~mm}$ dia. circular hollow section (CHS) steel piles between Hitchin and Carstairs (by way of Edinburgh), supporting the Mk3B $25 \mathrm{kVAC}$ OLE and associated masts. Historical records also reveal the successful application of the Master Series method to the design of foundations in alluvium and chalk, and to a more limited extent, peat. These geologies are excluded from the range of applicability of the ORE method given in the original UIC-ORE document.

\subsection{Analysis based on allowable lateral stresses: the Balfour Beatty Power Construction Ltd (BBPCL) method}

The BBPCL Foundation Design Manual (BBPCL, 1990) describes methods of design analysis based on allowable lateral stress distributions on piles in terms of both effective and total stresses (corresponding to drained and undrained conditions, respectively). These are illustrated in Figure 3. The effective stress distribution was originally proposed by Sulzberger (1945). Explanatory notes relating to the BBPCL approach are given in Table 3.

In both cases (drained and undrained), the net lateral stress distribution is automatically in horizontal equilibrium; hence an additional average lateral pressure in front of the foundation of $H /(L D)$ (where $L$ is the width of the foundation perpendicular 


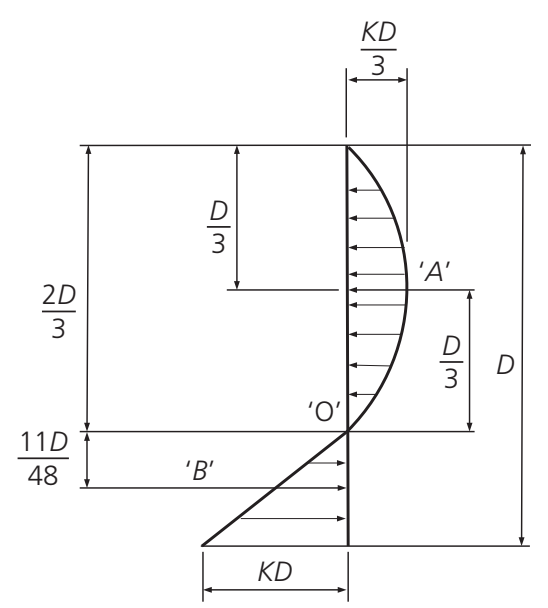

(a)

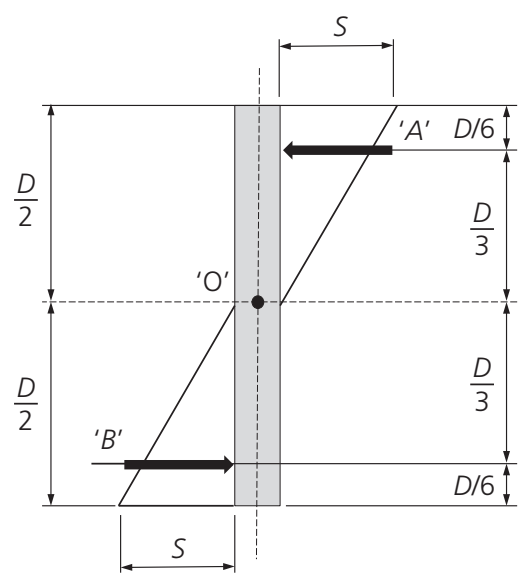

(b)

Figure 3. (a) Allowable net lateral effective and (b) total stress distributions on a pile foundation of effective length $D$, subjected to an overturning moment $M$ (redrawn from BBPCL, 1990)

Table 3. Explanatory notes for BBPCL allowable stress distributions given in Figure 3

\begin{tabular}{|c|c|c|c|c|}
\hline $\begin{array}{l}\text { Stress } \\
\text { distribution }\end{array}$ & $\begin{array}{l}\text { Height of 'centre of } \\
\text { overturning' above } \\
\text { base of foundation }\end{array}$ & $\begin{array}{l}\text { Moment about } \\
\text { centre of } \\
\text { overturning }\end{array}$ & $\begin{array}{l}\text { Soil stress } \\
\text { parameter }\end{array}$ & Notes on soil stress parameter \\
\hline Effective & $D / 3$ & $M=\frac{D^{3} K L}{12}$ & K & $\begin{array}{l}K \text { varies from } 200 \mathrm{kPa} / \mathrm{m} \text { for sandstone/limestone to } 80 \mathrm{kPa} / \mathrm{m} \text { for } \\
\text { medium dense sand. Method not recommended for loose materials }\end{array}$ \\
\hline Total & $D / 2$ & $P D^{2}(L+C)^{\mathrm{a}}$ & $S$ & $\begin{array}{l}\text { S varies from } 180 \mathrm{kPa} \text { for very stiff boulder clay to } 84 \mathrm{kPa} \text { for firm } \\
\text { clays. Method not recommended for medium/soft clays }\end{array}$ \\
\hline
\end{tabular}

$D$, foundation depth; $L$, foundation length on plan

${ }^{a}$ The width of the foundation, $L$, is increased by an amount $C(C=0.4 \mathrm{~m}$ for $L>1 \mathrm{~m}$ is suggested), to account for the fact that the supposed failure surface spreads out into the soil

to the direction of $H$, and $D$ is the effective depth of the foundation) would be needed to resist the net horizontal force, $H$.

Although the BBPCL method has been used successfully in the design of OLE mast pile foundations, it has fallen out of favour in recent times. Being based on permissible stresses, it does not readily fit within the framework of Eurocode 7 (BSI, 2013) and uses soil parameters whose determination is to an extent subjective. It will therefore not be considered further in this paper.

\subsection{Analysis based on limiting lateral stresses \\ (following Brinch Hansen, 1961; \\ Broms, 1964a, 1964b; Fleming et al., 1994, 2009)}

\subsubsection{Effective stresses}

The design approach developed for GWEP is based on factored limiting net lateral stress distributions. It broadly follows the approach given in textbooks such as Fleming et al. (2009), which is itself based on principles suggested by Brinch Hansen (1961) or Broms (1964a, 1964b).

The form of the limiting lateral stress distribution assumed for drained (effective stress) conditions is illustrated in Figure 4.

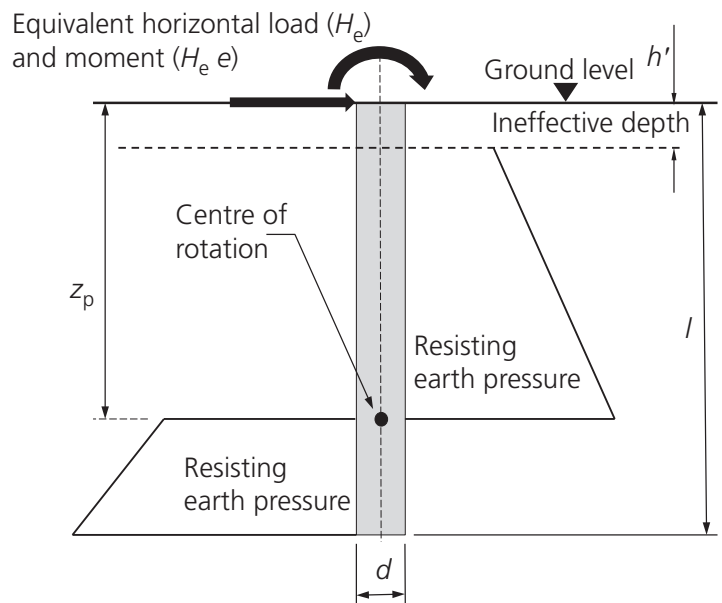

Figure 4. Net lateral stresses assumed in effective stress LEA of a laterally loaded pile

There are differences in the detail of the assumed limiting lateral stress distribution proposed by the various authors. 
Brinch Hansen (1961) bases the equivalent lateral stress near the surface on an assumed three-dimensional passive failure wedge, and includes an allowance for a contribution from friction on the sides. At great depth, failure is assumed to correspond to a bearing failure of the pile in the horizontal plane, hence involves a term in $K_{\mathrm{o}} K_{\mathrm{p}} \mathrm{e}^{\pi \tan \phi^{\prime}}$, where $K_{\mathrm{p}} \mathrm{e}^{\pi \tan \phi^{\prime}}$ is the bearing capacity factor, $N_{\mathrm{q}}$. To avoid a discontinuity in the lateral stress at failure between the two regimes, Brinch Hansen (1961) proposed an empirical formula to achieve a smooth transition between the values of net normalised lateral resistance, $\sigma_{\mathrm{h}}^{\prime} / \gamma_{z}$, at the surface and at great (infinite) depth.

Broms (1964b) proposes the use of a net normalised lateral resistance, $\sigma_{\mathrm{h}}^{\prime} / \gamma_{z}$, of $K_{\mathrm{p}}$ over the uppermost 1.5 pile diameters. Failure occurs by the formation of a conventional shallow passive wedge intersecting the soil surface; the apparent neglect of side friction on the wedge is conservative. At depths greater than 1.5 pile diameters, where failure occurs by the flow of soil around the pile, the net limiting lateral pressure is taken as $3 K_{\mathrm{p}} \gamma_{z}$. On the basis of data from Barton (1982), Fleming et al. (1994) propose an approach similar to Broms (1964b), but with a net normalised lateral resistance of $K_{\mathrm{p}}^{2}$ below a depth of 1.5 pile diameters. As explained below, the approach proposed by Broms (1964b) was adopted for the comparative analyses presented in this paper.

The key features of the effective stress limit equilibrium analyses (LEAs) carried out for the present study were that

- the loading system was taken as statically equivalent to a moment $M_{\mathrm{GL}}=H_{\mathrm{e}} e$ and an equivalent lateral load $H_{\mathrm{e}}$, both acting at the top of the foundation (ground level)

- the pile is of diameter $d$ and total length $l$, and rotates about a 'pivot point' at a depth $z_{\mathrm{p}}$ below ground level

- where the pile moves into the soil (i.e. in front of the pile above the pivot point and behind the pile below it), passive pressures are developed; the net passive pressure is given by $K_{\mathrm{p}}$ times the nominal vertical effective stress $\left(\gamma^{*} z\right.$, where $\left.\gamma^{*}=\gamma-(\mathrm{d} u / \mathrm{d} z)\right)$, down to a depth of 1.5 times the pile diameter $d$; and $3 K_{\mathrm{p}}$ times the nominal vertical effective stress below this depth, where $K_{\mathrm{p}}$ is the passive pressure coefficient

- the equations of moment and horizontal force equilibrium were used to find the two unknown depths, $l$ and $z_{\mathrm{p}}$

- active pressures in zones where the pile is supposed to be moving away from the soil were assumed to be small and were ignored

- the vertical load on the foundation is assumed to be carried in base bearing.

There may be some uncertainty concerning the appropriate value of passive pressure coefficient $K_{\mathrm{p}}$ - in particular, whether it should take a numerical value that reflects possible interface friction between the pile and the soil. This could make a very significant difference. For example, for $\phi^{\prime}=30^{\circ}, K_{\mathrm{p}}$ without friction is 3 whereas $K_{\mathrm{p}}$ with full interface friction, $\delta=\phi^{\prime}$, is $5 \cdot 67$.

Brinch Hansen (1961) used values of passive pressure coefficient for a frictional pile having $\delta=\phi^{\prime}$. In contrast, Fleming et al. (1994) used values of $K_{\mathrm{p}}$ based on the classical expression

$$
\text { 7. } K_{\mathrm{p}}=\frac{\left(1+\sin \phi^{\prime}\right)}{\left(1-\sin \phi^{\prime}\right)}
$$

for a pile/soil interface friction angle $\delta=0$.

The original work that led to the expressions for limiting lateral resistance of $3 K_{\mathrm{p}}$ and $K_{\mathrm{p}}^{2}$ was based on tests carried out in sandy soils, with values of angle of shearing resistance $\phi^{\prime}$ likely to have been in excess of $30^{\circ}$ (i.e. for which $K_{\mathrm{p}}^{2}>3 K_{\mathrm{p}}$ ). Pan et al. (2012) reported three-dimensional finite-element analyses of laterally loaded piles in a soil having $\phi^{\prime}=20^{\circ}$. Computed limiting lateral pressures were bracketed by $K_{\mathrm{p}}^{2}$ with $K_{\mathrm{p}}$ calculated using a pile/soil interface angle of friction $\delta=\phi^{\prime}$, and $3 K_{\mathrm{p}}$ calculated using $\delta=0$. This suggests that the conventional approach of taking a limit defined by $K_{\mathrm{p}}^{2}$ with $K_{\mathrm{p}}$ calculated using $\delta=0$ may be conservative for lower strength soils. In general, however, the work of Pan (2013) supports the use of Equation 7 - which assumes a pile/soil interface friction angle $\delta=0$ - to calculate $K_{\mathrm{p}}$ in the empirical formulae for determining limiting lateral pile pressures, as in Fleming et al. (1994).

The use of Equation $7(\delta=0)$ is further supported by the likely need to invoke shear stresses acting tangentially on the pile (to carry torque), and/or vertically (to help carry vertical load, if the base bearing pressure is not sufficient). It could thus be unsafe to assume that soil/pile interface shear stresses in possibly a different direction will be available to enhance the lateral stresses on the pile. It was therefore decided to calculate values of $K_{\mathrm{p}}$ using Equation 7, without any enhancement for soil/pile friction effects.

Where the pile is being pushed towards the outer face of an embankment of slope $\beta$, Equation 7 may be modified to take account of the rotation in principal stresses that occurs between the pile and the soil surface as a result of the slope. If the ratio of the slope angle $\beta$ to the effective soil friction angle $\phi^{\prime}$ is high, the modified value of $K_{\mathrm{p}}$ may be less than 1 . For this reason, three-dimensional effects were represented in the current calculations by an effective lateral pressure coefficient of $3 K_{\mathrm{p}}$ (following Broms, 1964b), rather than $K_{\mathrm{p}}^{2}$ (following Fleming et al., 1994).

A further point concerns the relationship between the surface zone soil of 1.5 times the pile diameter $d$ (in which the limiting lateral stresses are taken as $K_{\mathrm{p}}$, rather than $3 K_{\mathrm{p}}$ or $K_{\mathrm{p}}^{2}$ times the vertical effective stresses) and the UIC-ORE ineffective depth 
of disturbed, replaced or otherwise unconsolidated soil near the top of the foundation. It seems reasonable that the ineffective surface layer would at least act as a surcharge on the soil below it, enabling the 'at depth' failure mechanism to develop below a depth of 1.5 times the pile diameter $d$. Thus, provided that the thickness of the ineffective layer is at least $1.5 d$, the lateral stress may reasonably be taken as $3 K_{\mathrm{p}}$ times the vertical effective stress at all depths below it. This assumption has been made here; it also has the benefit of simplifying the calculations. The ground in the vicinity of a railway line is likely to be well compacted by trafficking, in which case the assumption of an ineffective zone is conservative.

\subsubsection{Total stresses}

Limiting net total lateral stress distributions for laterally loaded piles, following Fleming et al. (1994, 2009), are shown in Figure 5 for three different ranges of pile length/diameter ratio, $l / d$.

As with the effective stress analysis

- the pile is subject to an equivalent horizontal load $H_{\mathrm{e}}$ acting at a height $e$ above the top of the foundation (ground level), giving a moment at ground level $M_{\mathrm{GL}}=H_{\mathrm{e}} e$

- the pile is of diameter $d$ and total length $l$, and rotates about a 'pivot point' at a depth $z_{\mathrm{p}}$ below ground level

- where the pile moves into the soil (i.e. in front of the pile above the pivot point and behind the pile below it), at limiting equilibrium passive pressures are developed; active pressures where the pile is moving away from the soil are ignored as being insignificant (and possibly tensile)

- the implied failure mechanism in the soil changes from a three-dimensional passive wedge near the surface to soil flowing horizontally around the pile at greater depths, where the vertical stress is sufficient to suppress upward movement of the soil

- the equations of moment and horizontal force equilibrium are used to find the two unknown depths, $l$ and $z_{\mathrm{p}}$

a separate check would need to be carried out on the vertical load capacity of the pile.

In this case, the limiting lateral load per unit pile depth, $p_{\mathrm{u}}$ (i.e. the limiting lateral total stress, $\sigma_{\mathrm{h}}$, multiplied by the pile diameter, $d$ ) is taken as zero over the assumed ineffective depth of $1 \cdot 5 d$, then

8. $p_{\mathrm{u}}=\left[2+\frac{7(z-1 \cdot 5 d)}{3 d}\right] c_{\mathrm{u}} d$ for depths $1.5 d \leq z \leq 4.5 d$

and

9. $\quad p_{\mathrm{u}}=9 c_{\mathrm{u}} d$ for depths $z \geq 4.5 d$

following Fleming et al., 1994).

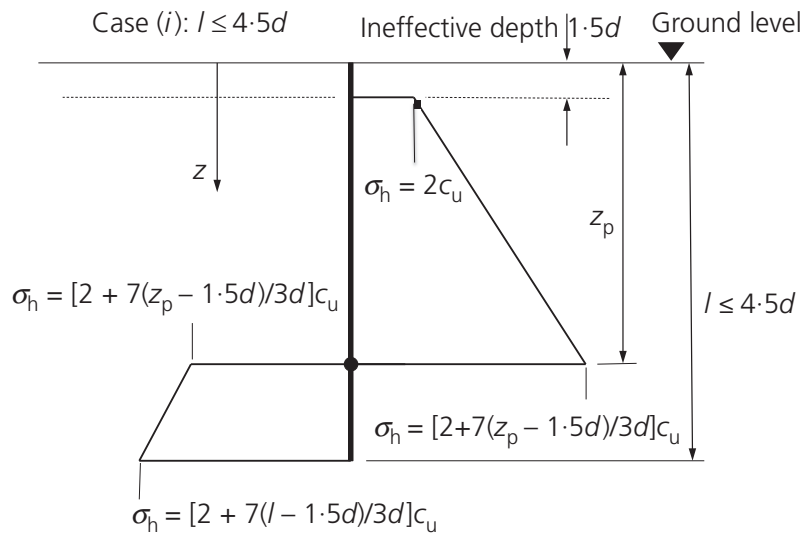

(a)

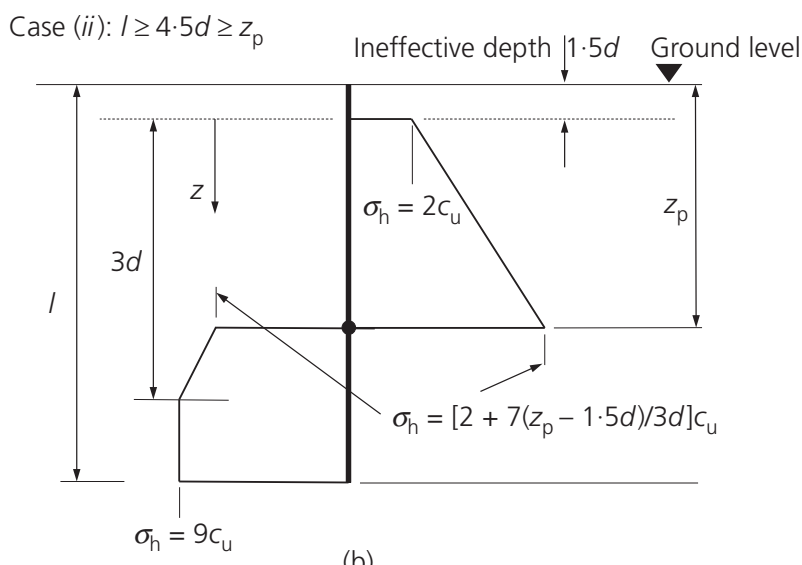

(b)

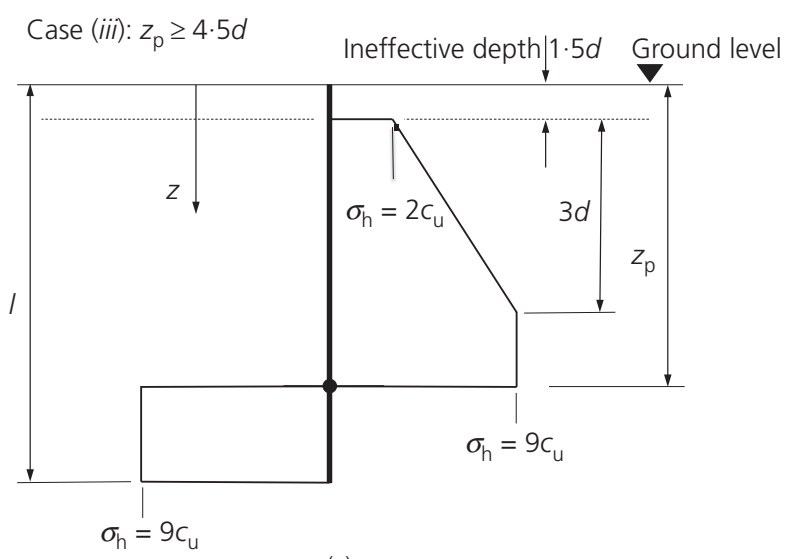

(c)

Figure 5. Limiting total lateral stresses on a laterally loaded pile in a clay soil characterised by the undrained shear strength, $\mathrm{C}_{\mathrm{u}}$ : (a) $I \leq 4.5 d$; (b) $z_{\mathrm{p}} \leq 4.5 d \leq l$; (c) $z_{\mathrm{p}} \geq 4.5 d$

The maximum value of $p_{\mathrm{u}}$ is just less than that determined analytically for a frictionless pile by Randolph and Houlsby (1984), leaving vertical and tangential shear stress capacity to carry vertical load and torque. 


\subsubsection{Implementation within Eurocode 7}

In both the effective and total limiting lateral stress analyses, it is necessary in design to apply partial factors as required by Eurocode 7 (BSI, 2013, p. 33). Design approach 1 (DA1), in which partial factors are applied to actions $(A)$ and ground strength parameters $(M)$, is adopted in the UK. For structures other than axially loaded piles, the designer must verify that 'a limit state of rupture or excessive deformation will not occur with either of the following combinations of sets of partial factors.

Combination 1: $A 1+M 1+R 1$

Combination 2: $A 2+M 2+R 1$.'

The numerical values of sets $A 1, A 2, M 1$ and $M 2$ of these partial factors are reproduced in Table 4; the partial factors in set $R 1$ are numerically equal to unity.

Table 4. Partial factors sets $A 1, A 2, M 1$ and $M 2$ from Eurocode 7 (values in R1 are equal to 1.0)

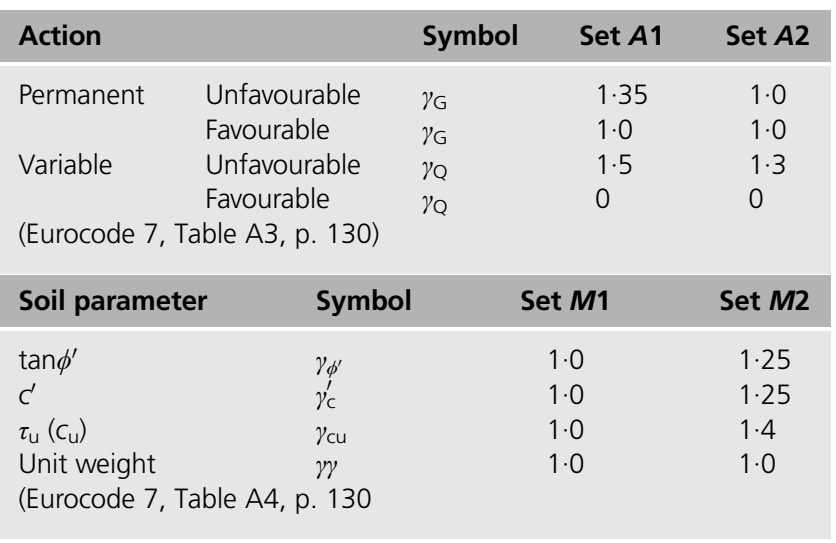

It is generally held that combination 2 will usually give the most onerous geotechnical conditions (greatest pile length, depth of embedment, etc.). However, both combinations must be checked.

Applying the relevant partial factors to the characteristic permanent (self-weight) and variable (wind, etc.) loads identified in Table 1 for a wind with a 50 year return period gives the factored loads for each type of structure indicated in Table 5 . The corresponding characteristic loads for use in the ORE/OLEMI calculation are also shown.

In the case of OLE support masts, the major variable load is due to wind, which is assessed on a statistical basis as for example having a 50 year return period (i.e. a probability of $2 \%$ of being exceeded in any given year). That trains are unlikely to be running in such conditions is reflected in guidance on wind loading of OLE structures (Network Rail, 2015b) by the relaxation of the need for the structure to meet the serviceability (displacement) requirement under the 50 year return period wind loading.

\section{Comparative calculations}

Calculations have been carried out to compare the results of the OLEMI and limit equilibrium approaches; the latter in both drained (effective stress) and undrained (total stress) conditions (ORE/OLEMI does not draw a distinction). The characteristic loads, topography and soil conditions investigated are summarised in Table 6 .

In the effective stress limit equilibrium approach, values of $K_{\mathrm{p}}$ were determined using Equation 10, to account for the effect of the embankment slope angle $\beta\left(\beta \leq \phi^{\prime}\right)$, assuming a soil/pile

Table 5. Factored loads associated with three types of Series 1 OLE structure for different design methods (50 year wind return period)

\begin{tabular}{|c|c|c|c|c|}
\hline & & STC & TTC & XL-TTC \\
\hline \multicolumn{5}{|c|}{ (a) Across track } \\
\hline Eurocode 7 & Factored $H_{\mathrm{e}}: \mathrm{kN}$ & $21 \cdot 456$ & 32.982 & $44 \cdot 1$ \\
\hline \multirow[t]{2}{*}{ DA1 C 1} & Factored $M_{\mathrm{GL}}: \mathrm{kNm}$ & $139 \cdot 5015$ & 273.899 & $597 \cdot 645$ \\
\hline & Equivalent height of load, e: $\mathrm{m}$ & $6 \cdot 502$ & $8 \cdot 304$ & 13.552 \\
\hline Eurocode 7 & Factored $H_{\mathrm{e}}: \mathrm{kN}$ & $18 \cdot 398$ & $28 \cdot 19$ & $38 \cdot 22$ \\
\hline \multirow[t]{2}{*}{ DA1 C2 } & Factored $M_{\mathrm{GL}}: \mathrm{kNm}$ & $118 \cdot 574$ & $226 \cdot 565$ & $487 \cdot 24$ \\
\hline & Equivalent height of load, e: $\mathrm{m}$ & $6 \cdot 445$ & 8.037 & $12 \cdot 748$ \\
\hline ORE/OLEMI & Characteristic $M_{\mathrm{GL}}: \mathrm{kNm}$ & $94 \cdot 37$ & $188 \cdot 96$ & $416 \cdot 5$ \\
\hline \multicolumn{5}{|c|}{ (b) Away from track } \\
\hline Eurocode 7 & Factored $H_{\mathrm{e}}: \mathrm{kN}$ & $18 \cdot 324$ & $26 \cdot 718$ & $44 \cdot 1$ \\
\hline DA1 C 1 & $\begin{array}{l}\text { Factored } M_{\mathrm{GL}}: \mathrm{kNm} \\
\text { Equivalent height of load, e: } \mathrm{m}\end{array}$ & $\begin{array}{r}102.539 \\
5.596\end{array}$ & $\begin{array}{c}102.1515 \\
3.823\end{array}$ & $\begin{array}{r}109.755 \\
2.489\end{array}$ \\
\hline Eurocode 7 & Factored $H_{\mathrm{e}}: \mathrm{kN}$ & $16 \cdot 078$ & $23 \cdot 55$ & $38 \cdot 22$ \\
\hline DA1 C2 & $\begin{array}{l}\text { Factored } M_{\mathrm{GL}}: \mathrm{kNm} \\
\text { Equivalent height of load, e: } \mathrm{m}\end{array}$ & $\begin{array}{r}91.194 \\
5.672\end{array}$ & $\begin{array}{r}99 \cdot 345 \\
4 \cdot 218\end{array}$ & $\begin{aligned} 125.84 \\
3.293\end{aligned}$ \\
\hline ORE/OLEMI & Characteristic $M_{\mathrm{GL}}: \mathrm{kNm}$ & 66.99 & 61.74 & $55 \cdot 10$ \\
\hline
\end{tabular}

Note: The ORE/OLEMI calculation takes only the characteristic load (additional partial factors are not applied); this is purely in terms of a moment, not a lateral force and a height of action 
Table 6. Characteristic loads, topography and soil conditions investigated in comparative calculations

\begin{tabular}{ll} 
Structures considered & STC; TTC; XL-TTC \\
\hline Loads (horizontal load, $H_{\mathrm{e}}$, and equivalent height of action, e, or moment at ground level, $M_{\mathrm{GL}}$ ) & See Table 5 \\
Soil unit weight, $\gamma: \mathrm{kN} / \mathrm{m}^{3}$ & 18 \\
Soil effective unit weight, $\gamma^{*}=\gamma-(\mathrm{d} u / \mathrm{dz} z): \mathrm{kN} / \mathrm{m}^{3}$ (and corresponding pore water pressure & $18(\mathrm{du} / \mathrm{d} z=u=0)$ (zero pore water pressures) \\
$\quad$ gradient $\mathrm{d} u / \mathrm{d} z)$ & $8(\mathrm{du} / \mathrm{dz}=10 \mathrm{kPa} / \mathrm{m})($ hydrostatic) \\
Soil effective angle of shearing resistance, $\phi^{\prime}:$ degrees (effective stress LEAs) & $20 ; 321 / 2 ; 45$ \\
Soil undrained shear strength, $C_{\mathrm{u}}: \mathrm{kPa}$ (total stress LEA) & $30 ; 60 ; 120$ \\
Embankment slope angle, $\beta$ : degrees & 0 to 40 (maximum) \\
Location of foundation & At embankment crest
\end{tabular}

friction angle $\delta=0$

10. $K_{\mathrm{p}}=\frac{\sigma_{\mathrm{h}}^{\prime}}{\gamma_{z}}=\frac{\cos ^{2} \beta(1+\sin \theta) \times \mathrm{e}^{2 \theta \tan \phi^{\prime}}}{\left[1-\sin \phi^{\prime} \cos \left(\Delta_{1}-\beta\right)\right]}$

where

11. $\theta=-\left(\frac{\Delta_{1}+\beta}{2}\right)$

and

12. $\sin \Delta_{1}=\frac{\sin \beta}{\sin \phi^{\prime}}$

Equation 10 was derived using the principles of stress analysis set out in, for example, Powrie (2014). It is approximate, as there may in reality be insufficient space within the embankment to accommodate the implied rotation in the principal stress direction between the pile and the soil surface.

In the total stress analysis, the effect of the embankment slope in reducing the limiting lateral earth pressures is more difficult to account for simply, as the geometry of the Mohr circle of stress associated with the undrained shear strength failure criterion leads to a non-linearity with depth. For a horizontal force in the direction away from the track, finite-element analyses by Georgiadis and Georgiadis (2010) suggest that the slope may reduce the ultimate lateral resistance to pile movement by a maximum of about $20 \%$, while field tests by Nimityongskul et al. (2018) show that the slope has no noticeable effect for piles installed on the crest at or beyond a horizontal distance of eight pile diameters from the top of the slope. However, for OLE structures, the greater horizontal force is usually in the direction towards the track. Finiteelement analyses by Kanagasabai et al. (2011) suggest that, in this case, where the net lateral stress on the pile is acting downslope, a slope angle of up to at least $22^{\circ}$ makes little difference to the ultimate lateral pressure on the pile. Hence results of total stress analyses are presented only for level ground, $\beta=0$.
In all calculations, the pile was circular in cross-section with an outside diameter $d=0.61 \mathrm{~m}$, and an ineffective depth of $0.915 \mathrm{~m}(1.5$ times the pile diameter $)$ was assumed.

The limit equilibrium calculations were carried out using the factored loads (C1 or $\mathrm{C} 2)$ indicated in Table 5, and factored soil strengths $(\mathrm{C} 2)$ as required by Eurocode 7 . In all cases, $\mathrm{C} 2$ gave greater pile lengths than $\mathrm{C} 1$. Calculations were carried out for across-track wind loads acting both towards and away from the track. In most cases, the first (where the wind moment acts with the structural load) gave the greater pile length. However, at steeper embankment slopes, the second (with a smaller applied moment) gave the greater pile length, because the dominant effect was the reduced ground resistance due to the presence of the slope when the pile is pushed outward towards the surface of the embankment.

No further factors were applied in the OLEMI calculations, as the required load factors are already included in the equations.

Results are presented for the effective stress LEAs in drained ground with zero pore water pressures, as graphs of the

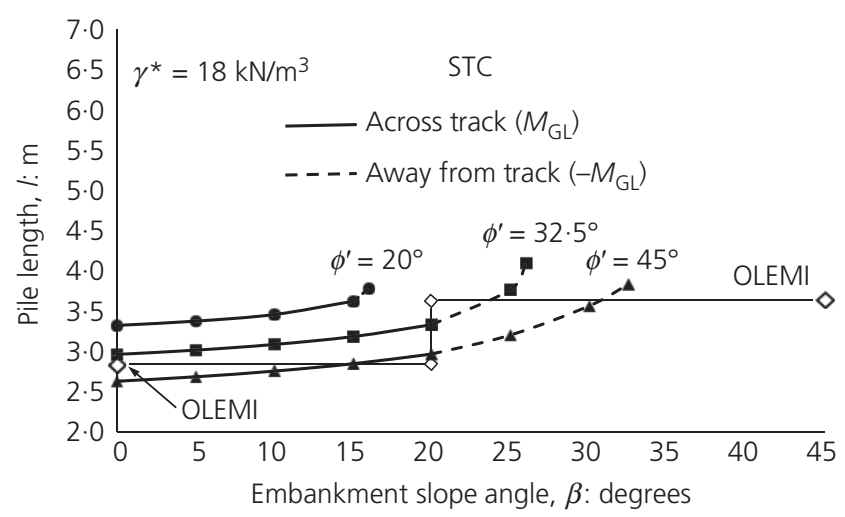

Figure 6 . Pile length $/$ as a function of slope angle $\beta$, for soil effective friction angles of $20,32.5$ and $45^{\circ}$. STC, effective stress limit equilibrium and OLEMI analyses with zero pore water pressures. Soil-pile interface friction angle $\delta=0$. All necessary load and strength factors applied. Soil unit weight $18 \mathrm{kN} / \mathrm{m}^{3}$. Note: the soil strengths indicated apply only to the limit equilibrium calculations - the OLEMI method does not use the soil strength, only the unit weight/density 
required pile embedment depth $l$ against the embankment slope angle $\beta$, for values of $\phi^{\prime}$ of $20^{\circ}, 32.5^{\circ}$ and $45^{\circ}$, for the STC, the TTC and the XL-TTC in Figures 6, 7 and 8, respectively. The corresponding results for waterlogged ground with hydrostatic pore water pressure conditions $(\mathrm{d} u / \mathrm{d} z=10 \mathrm{kPa} / \mathrm{m})$ are shown in Figures 9, 10 and 11, respectively.

Results for the undrained (total stress) LEAs are presented non-dimensionally in Figure 12 as graphs of the required pile length/diameter ratio $(l / d)$ against normalised horizontal load $H_{\mathrm{e}} e / c_{\mathrm{u}} d^{2}$, for normalised heights of action of $H_{\mathrm{e}}(e / d)$ of $3 \cdot 5$,

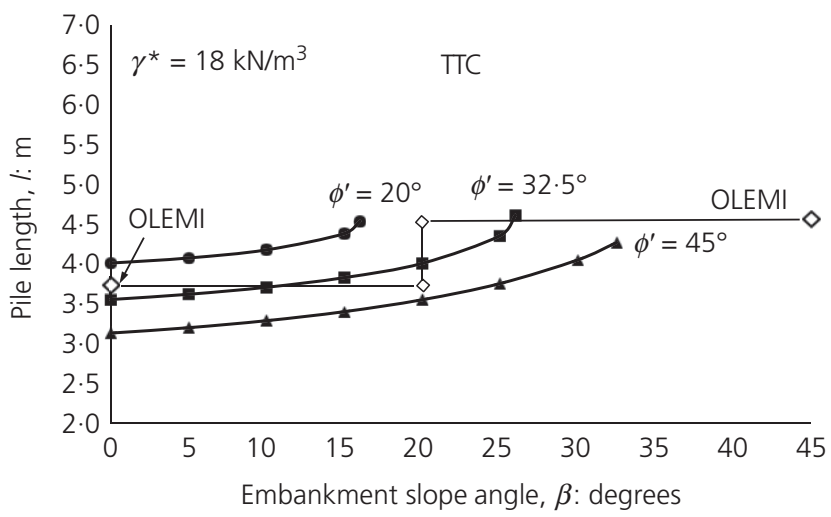

Figure 7. Pile length, $I$, as a function of slope angle $\beta$, for soil effective friction angles of $20,32.5$ and $45^{\circ}$. TTC, effective stress limit equilibrium and OLEMI analyses with zero pore water pressures. Soil-pile interface friction angle $\delta=0$. All necessary load and strength factors applied. Soil unit weight $18 \mathrm{kN} / \mathrm{m}^{3}$. Note: the soil strengths indicated apply only to the limit equilibrium calculations - the OLEMI method does not use the soil strength, only the unit weight/density

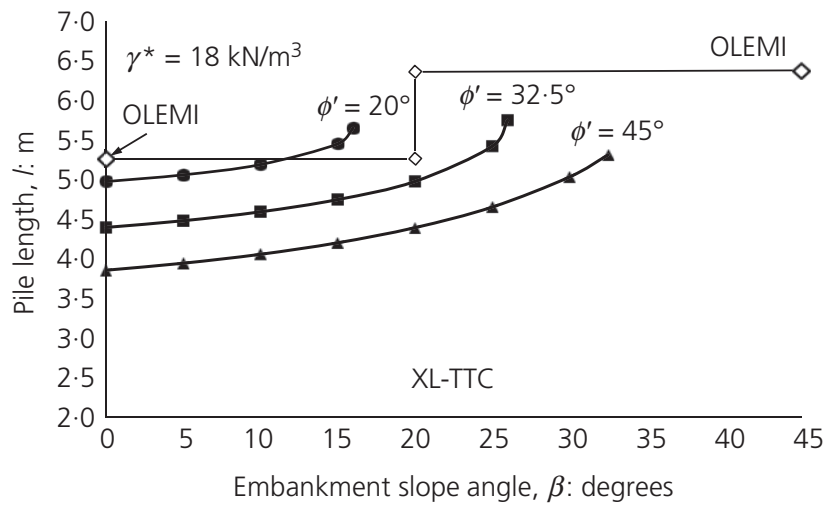

Figure 8. Pile length, $I$, as a function of slope angle $\beta$, for soil effective friction angles of $20,32.5$ and $45^{\circ}$. XL-TTC, effective stress limit equilibrium and OLEMI analyses. Soil-pile interface friction angle $\delta=0$. All necessary load and strength factors applied. Soil unit weight $18 \mathrm{kN} / \mathrm{m}^{3}$. Note: the soil strengths indicated apply only to the limit equilibrium calculations - the OLEMI method does not use the soil strength, only the unit weight/density
$8 \cdot 5,13 \cdot 5$ and $23 \cdot 5$ (which covers the range for the OLE masts under consideration; see Table 5). Numerical values of pile length $l$, including the ineffective depth of $1 \cdot 5 d$, for the STC, TTC and XL-TTC with the appropriate partial factors applied to loads and soil strengths are compared with the OLEMIderived lengths for level ground $(\beta=0)$ in Table 7 . In the limit equilibrium calculations in level ground, towards-track loading with the partial factors associated with DA1 combination 2

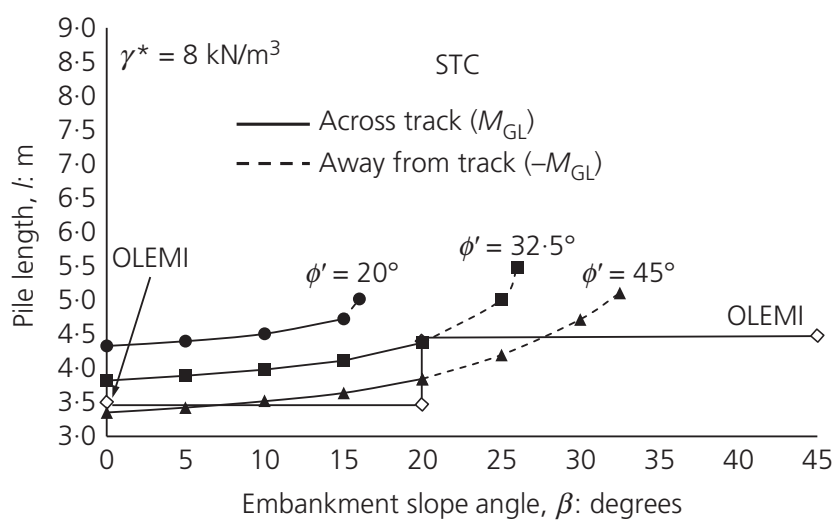

Figure 9. Pile length, $I$, as a function of slope angle $\beta$, for soil effective friction angles of $20,32.5$ and $45^{\circ}$. STC, effective stress limit equilibrium and OLEMI analyses with hydrostatic pore water pressures below a water table at the ground surface. Soil-pile interface friction angle $\delta=0$. All necessary load and strength factors applied. Soil unit weight $18 \mathrm{kN} / \mathrm{m}^{3}$ (effective unit weight $8 \mathrm{kN} / \mathrm{m}^{3}$ ). Note: the soil strengths indicated apply only to the limit equilibrium calculations - the OLEMI method does not use the soi strength, only the unit weight/density

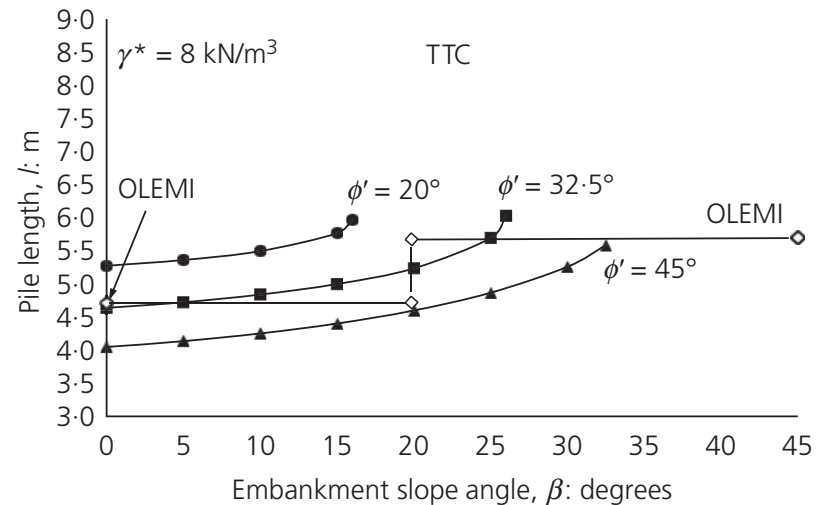

Figure 10. Pile length, $I$, as a function of slope angle $\beta$, for soil effective friction angles of $20,32.5$ and $45^{\circ}$. TTC, effective stress limit equilibrium and OLEMI analyses with hydrostatic pore water pressures below a water table at the ground surface. Soil-pile interface friction angle $\delta=0$. All necessary load and strength factors applied. Soil unit weight $18 \mathrm{kN} / \mathrm{m}^{3}$ (effective unit weight $8 \mathrm{kN} / \mathrm{m}^{3}$ ). Note: the soil strengths indicated apply only to the limit equilibrium calculations - the OLEMI method does not use the soil strength, only the unit weight/density 
The design of railway overhead line

equipment mast foundations

Powrie, Richards and Mootoosamy

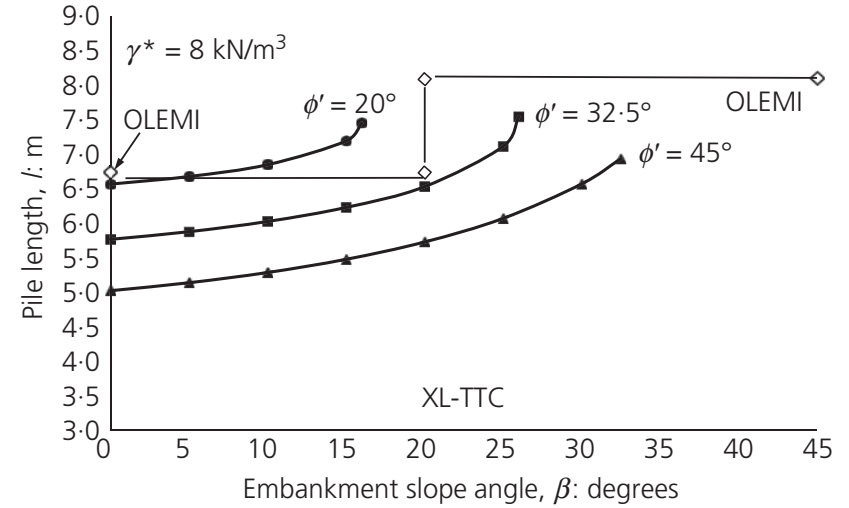

Figure 11. Pile length, $I$, as a function of slope angle $\beta$, for soil effective friction angles of $20,32.5$ and $45^{\circ}$. XL-TTC, effective stress limit equilibrium and OLEMI analyses with hydrostatic pore water pressures below a water table at the ground surface. Soil-pile interface friction angle $\delta=0$. All necessary load and strength factors applied. Soil unit weight $18 \mathrm{kN} / \mathrm{m}^{3}$ (effective unit weight $8 \mathrm{kN} / \mathrm{m}^{3}$ ). Note: the soil strengths indicated apply only to the limit equilibrium calculations - the OLEMI method does not use the soil strength, only the unit weight/density

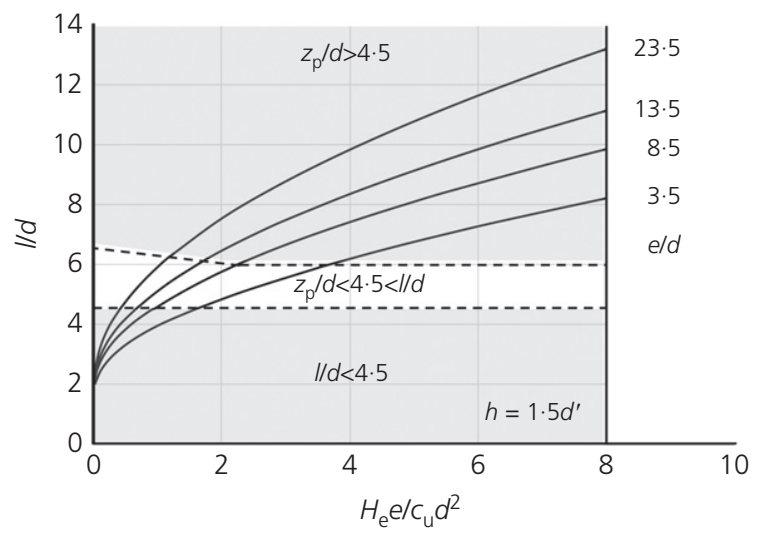

Figure 12. Dimensionless pile length $/ / d$ as a function of dimensionless load $\mathrm{H}_{\mathrm{e}} / \mathrm{C}_{\mathrm{u}} d^{2}$, for normalised heights of action of $\mathrm{H}_{\mathrm{e}}$ (e/d) of $3.5,8.5,13.5$ and 23.5; total stress LEAs (slope $\beta=0$, ineffective pile depth of $1.5 d$ included) (including a factor of 1.4 on the undrained shear strength of the soil) was always the most onerous condition.

\section{Commentary}

Generally, the results of the two methods of calculation are, perhaps surprisingly, broadly consistent.

\subsection{Effective stress analyses}

For the effective stress analyses

in level ground $(\beta=0)$ with zero pore water pressures, the OLEMI calculation gives an embedment depth just less than the LEA with $\phi^{\prime}=32 \cdot 5^{\circ}$ for the STC (Figure 6), just greater than the LEA with $\phi^{\prime}=32.5^{\circ}$ for the TTC (Figure 7), and greater than the LEA $\phi^{\prime}=20^{\circ}$ for the XL-TTC (Figure 8)

- in waterlogged level ground $(\beta=0)$ with hydrostatic pore water pressures, the difference between the two calculations for the STC (Figure 9) is increased slightly (i.e. the OLEMI calculation is relatively more unconservative), but for the TTC (Figure 10) and the XL-TTC (Figure 11) there is no real relative change

- as the slope angle is increased, the OLEMI calculation (which is insensitive to slope angles $\beta<20^{\circ}$ ) gives increasingly more unconservative (i.e. relatively shorter) pile lengths (Figures 6-11)

- at a slope of $20^{\circ}$, there is a step change in the OLEMI pile length which makes it greater than that calculated by the LEA for $\phi^{\prime}=32.5^{\circ}$ and $\phi^{\prime}=45^{\circ}$ (Figures 6-11)

a as the slope angle is increased towards $45^{\circ}$, the OLEMI calculation for the STC (Figures 6 and 9) gradually becomes unconservative again, first relative to the limit equilibrium calculation for $\phi^{\prime}=32 \cdot 5^{\circ}$ and then to that for $\phi^{\prime}=45^{\circ}$. However, this does not occur for the TTC

(Figures 7 and 10) or the XL-TTC (Figures 8 and 11). For these structures, the OLEMI calculation consistently gives pile depths greater than the LEAs for $\phi^{\prime}=32 \cdot 5^{\circ}$ and $\phi^{\prime}=45^{\circ}$, except for the TTC with slope angles greater than about $25^{\circ}$ (waterlogged, Figure 10 ) or $26^{\circ}$ (zero pore water pressures, Figure 7) and $\phi^{\prime}=32 \cdot 5^{\circ}$ (Figures 7 and 10). Also, it must be recognised that the maximum slope using the OLEMI approach of $45^{\circ}$ is greater than the maximum slope permitted with any of the effective stress analyses having $\phi^{\prime} \leq 45^{\circ}$ (Figures 6-11).

Table 7. Comparison of OLEMI-derived values with the most onerous pile lengths, I (including the ineffective depth of 1.5d), for the STC, TTC and XL-TTC (DA1 C2 for towards-track loading, with the appropriate partial factors applied to loads and soil strengths) calculated in total stress LEAs $(\beta=0)$

\begin{tabular}{lcccc}
\multicolumn{5}{c}{ LEA (DA1 C2, towards track) } \\
\cline { 2 - 5 } Pile lengths: $\boldsymbol{m}$ & $c_{\mathrm{u}}=\mathbf{3 0} \mathrm{kPa}$ & $c_{\mathrm{u}}=60 \mathrm{kPa}$ & $\boldsymbol{c}_{\mathrm{u}}=120 \mathrm{kPa}$ & OLEMI pile lengths: $\mathbf{m}$ \\
STC & 3.96 & 3.13 & 2.56 & 2.83 \\
TTC & 4.90 & 3.80 & 3.02 & 3.73 \\
XL-TTC & 6.30 & 4.80 & 3.75 & 5.26
\end{tabular}


It is notable that, for the XL-TTC (Figures 8 and 11), the OLEMI calculation always gives a greater pile depth than the LEA except for moderate slopes with $\phi^{\prime}=20^{\circ}$.

\subsection{Total stress analyses}

For the total stress analyses in level ground (Table 7)

- the OLEMI calculation gives pile lengths between those calculated using the LEA for undrained shear strengths of $60 \mathrm{kPa}$ and $30 \mathrm{kPa}$ for the TTC and the XLTTC, and between those calculated for undrained shear strengths of $120 \mathrm{kPa}$ and $60 \mathrm{kPa}$ for the STC. The equivalent undrained shear strength reduces from about $78 \mathrm{kPa}$ for the STC through $58 \mathrm{kPa}$ for the TTC to $33 \mathrm{kPa}$ for the XL-TTC.

Thus the OLEMI approach becomes relatively less unconservative or even more conservative compared with the LEA as the foundation moment is increased, in both the undrained and drained analyses.

\subsection{Summary}

Overall, the degree of unconservatism of the OLEMI approach compared with the LEA is only really a potential concern for relatively small loads (i.e. the STC) in soil having a relatively low effective angle of shearing resistance $\left(\phi^{\prime} \sim 20^{\circ}\right)$. These soils are likely to be clays, for which an undrained analysis of their response to short-term, transient loading is likely to be appropriate. In these conditions, the OLEMI method is generally conservative, unless the undrained shear strength of the ground is less than $78 \mathrm{kPa}$ for the STC and less than $33 \mathrm{kPa}$ for the XL-TTC. It must also be recalled that the Broms-type limit equilibrium calculation is itself far from rigorous, especially for the effective stress analysis; it involves significant assumptions, approximations, empiricism and uncertainty, as has already been discussed in this paper.

\section{Discussion and further analysis in the context of the GWEP}

Given the broad consistency between the results of the limit equilibrium and OLEMI methods, in both drained (zero pore water pressure) and waterlogged (hydrostatic) conditions, the question arises - although not the main thrust of this paper - as to why the early design calculations associated with GWEP seemed to result in excessive pile embedment depths. For example, as-built drawings and records for OLE foundations installed at Langley, Berkshire, indicate installed pile lengths of 6.5 to $7.0 \mathrm{~m}$ for $0.762 \mathrm{~m}$ dia. CHS piles subject to a characteristic across-track moment (associated with a TTC) of $140 \mathrm{kNm}$. Based on $\gamma^{*}=18 \mathrm{kN} / \mathrm{m}^{3}$, an ineffective depth $h^{\prime}=1.143 \mathrm{~m}$ $(1 \cdot 5 d)$, the OLEMI-calculated lengths for piles located on the crest of an embankment $(k=0 \cdot 95)$, in level ground $(k=1 \cdot 3)$ and in a cutting $(k=1.8)$ are $3.87,3.24$ and $2.89 \mathrm{~m}$, respectively. For waterlogged ground with $\gamma^{*}=8 \mathrm{kN} / \mathrm{m}^{3}$, the OLEMI-calculated lengths are $4.75 \mathrm{~m}$ on an embankment $(k=0.95), 3.99 \mathrm{~m}$ in level ground $(k=1 \cdot 3)$ and $3 \cdot 51 \mathrm{~m}$ in a cutting $(k=1 \cdot 8)$.
Calculations seen by the authors of this paper suggest two main reasons for the specification of such long pile lengths. These were overconservatism in $(a)$ the specified limiting lateral earth pressure coefficient (the authors have suggested the use of $3 K_{\mathrm{p}}$, calculated using a soil/pile friction angle $\delta=0$ ); and $(b)$ the equivalent linear soil stiffness parameters used in serviceability limit state (SLS) pile-soil interaction analyses.

\subsection{Limiting lateral earth pressure coefficient}

Calculations carried out using the program 'Wallap' for structures between Stockley and Maidenhead appear to have used a limiting passive earth pressure coefficient, $K_{\mathrm{p}}$, based on a pile/soil friction angle $\delta / \phi^{\prime}$ of $\approx 0 \cdot 45$, but without the enhancement factor of 3 to allow for three-dimensional effects. The results of further limit equilibrium calculations summarised in Figures 13-16 show that, in level ground, using $\delta / \phi^{\prime}=0.45$ makes very little difference compared with using $\delta=0$, but that the neglect of the empirical factor of 3 on $K_{\mathrm{p}}$ to allow for three-dimensional effects generally increases the calculated pile length by about $50 \%$ (compare Figure 6 with Figure 13 for a STC with a low groundwater level (GWL), Figure 8 with Figure 14 for an XL-TTC with a low GWL, Figure 9 with Figure 15 for a STC with a high GWL, and Figure 11 with Figure 16 for an XL-TTC with a high GWL).

\subsection{Effective (linear) soil stiffness}

The second issue arose from an attempt to carry out SLS assessments aimed at limiting the calculated structural deflection at wire height. The SLS was in the first initially rather poorly defined, owing to uncertainty about the permissible deflection (given the liveliness of the catenary itself, and the lateral stagger, i.e. designed-in to even out pantograph wear).

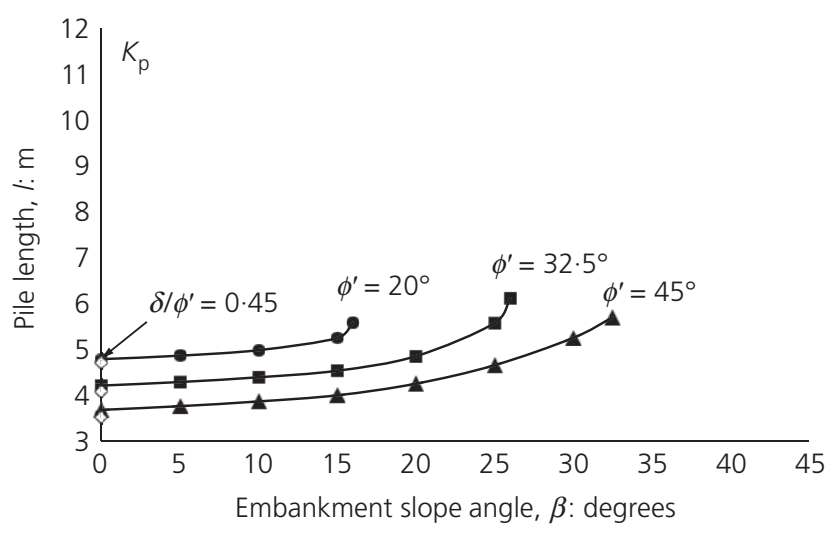

Figure 13. Pile length, $I$, as a function of slope angle, $\beta$, for soil effective friction angles of $20,32.5$ and $45^{\circ}$. STC, effective stress LEAs with the empirical enhancement factor of 3 to allow for three-dimensional effects omitted. Soil-pile interface friction angle $\delta=0$. All necessary load and strength factors applied. Zero pore water pressures, soil unit weight $18 \mathrm{kN} / \mathrm{m}^{3}$. The results of calculations for a slope angle $\beta=0$ and $\delta / \phi^{\prime}=0.45$ are also shown 
The design of railway overhead line

equipment mast foundations

Powrie, Richards and Mootoosamy

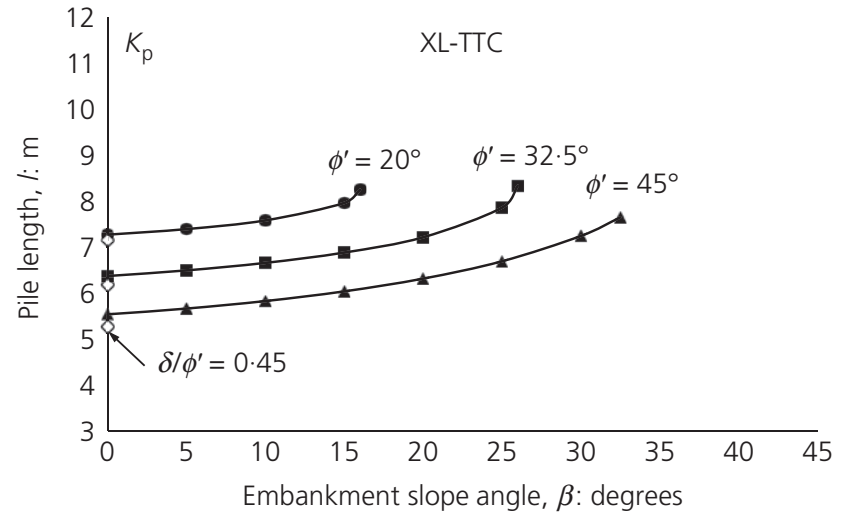

Figure 14. Pile length, $I$, as a function of slope angle, $\beta$, for soil effective friction angles of $20,32.5$ and $45^{\circ}$. XL-TTC, effective stress LEAs with the empirical enhancement factor of 3 to allow for three-dimensional effects omitted. Soil-pile interface friction angle $\delta=0$. All necessary load and strength factors applied. Zero pore water pressures, soil unit weight $18 \mathrm{kN} / \mathrm{m}^{3}$.

The results of calculations for a slope angle $\beta=0$ and $\delta / \phi^{\prime}=0.45$ are also shown

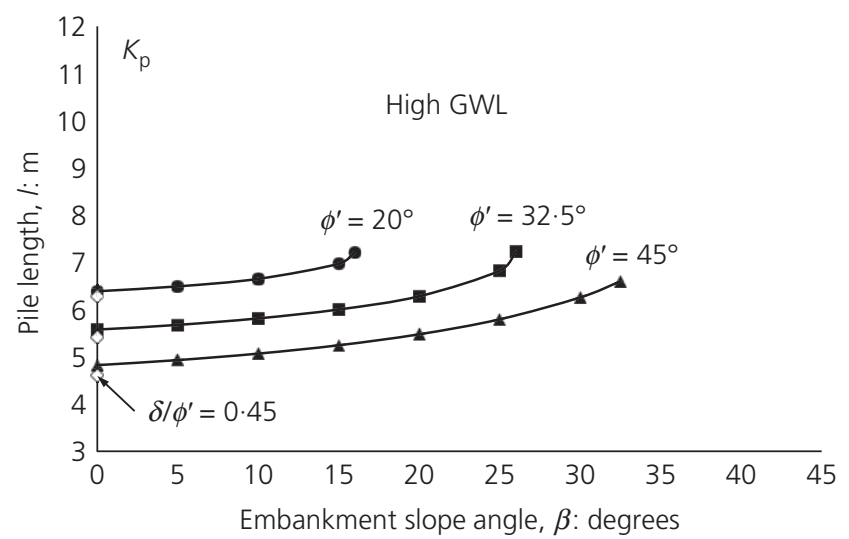

Figure 15. Pile length, $I$, as a function of slope angle, $\beta$, for soil effective friction angles of $20,32.5$ and $45^{\circ}$. STC, effective stress LEAs with hydrostatic pore water pressures below a water table at the ground surface, with the empirical enhancement factor of 3 to allow for three-dimensional effects omitted. Soil-pile interface friction angle $\delta=0$. All necessary load and strength factors applied. Soil unit weight $18 \mathrm{kN} / \mathrm{m}^{3}$ (effective unit weight $8 \mathrm{kN} / \mathrm{m}^{3}$ ). The results of calculations for a slope angle $\beta=0$ and $\delta / \phi^{\prime}=0.45$ are also shown

A further problem is that the calculated deflection and rotation at the pile head will often depend on the equivalent linear elastic soil stiffness chosen for use in the calculation. For example, Krechowiecki-Shaw and Alobaidi (2015) report the results of SLS calculations carried out using an effective Young's modulus of $15 \mathrm{MPa}$ for what is described as a medium dense sand. Young's moduli used in the calculations for structures between Maidenhead and Stockley Park (other than in the surface zone) ranged from $12 \mathrm{MPa}$ for a loose, sandy gravel to $60 \mathrm{MPa}$ for a medium dense gravelly sand.

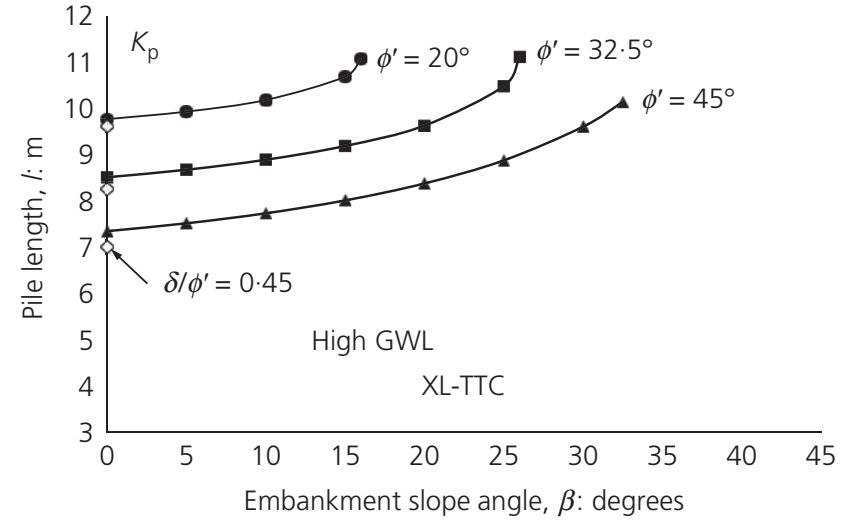

Figure 16. Pile length, $I$, as a function of slope angle, $\beta$, for soil effective friction angles of $20,32.5$ and $45^{\circ}$. XL-TTC, effective stress LEAs with hydrostatic pore water pressures below a water table at the ground surface, with the empirical enhancement factor of 3 to allow for three-dimensional effects omitted. Soilpile interface friction angle $\delta=0$. All necessary load and strength factors applied. Soil unit weight $18 \mathrm{kN} / \mathrm{m}^{3}$ (effective unit weight $8 \mathrm{kN} / \mathrm{m}^{3}$ ). The results of calculations for a slope angle $\beta=0$ and $\delta / \phi^{\prime}=0.45$ are also shown

It is difficult to find representative stiffnesses for granular soils in the literature. Nonetheless, recognising the Eurocode 7 requirement for the parameter value used in calculations to reflect the limit state under consideration (in this case, the SLS and therefore at small or moderate strains), some of these values do seem to be more appropriate to much less competent materials; for example, Duley (2019) measured an equivalent small strain Young's modulus of $12 \mathrm{MPa}$ for a very soft organic silt of bulk density $1 \cdot 2 \mathrm{Mg} / \mathrm{m}^{3}$ at a confining stress of $17 \mathrm{kPa}$.

To investigate the influence of foundation pile length and assumed soil stiffness on this potential SLS, the component of the horizontal deflection of the track support structure at wire height resulting from the deflection/rotation of the pile head was estimated using the Oasys (Oasys, 2017) program ALP (analysis of laterally loaded piles), as summarised in Appendix 3. Both an STC and an XL-TTC were considered, with soil Young's moduli of 15, 30 and $60 \mathrm{MPa}$ and pile lengths equal to one and two times those calculated using the OLEMI method for hydrostatic (i.e. worst case) pore water pressures: these loading and ground conditions are summarised in Table 8 .

The results of the ALP calculations, summarised in Figures 17 and 18 with the calculated wire height deflections given in Table 9, show the following.

In all cases, the calculated across-track wire height deflection due to the variable component of load is less than the limit of $50 \mathrm{~mm}$ specified in Network Rail Standard NR/SP/ELP/27215 (Network Rail, 2004).

- For the STC and a $3.5 \mathrm{~m}$ pile length, the calculated deflection is approximately linearly dependent on the 
Table 8. Input parameters and assumptions for ALP analyses

\begin{tabular}{|c|c|}
\hline Parameter & Value/assumptions \\
\hline $\begin{array}{l}\text { Applied loading (moment at ground level): } \\
\text { from Table } 1\end{array}$ & $94 \cdot 37$ kNm (STC): $416 \cdot 5$ kNm (XL-TTC) \\
\hline $\begin{array}{l}\text { Ratio variable to total moment at ground level } \\
\text { (from Table 1) }\end{array}$ & 0.855 (STC): 0.566 (XL-TTC) \\
\hline Pile diameter, $d(\mathrm{~m})$; wall thickness, $t(\mathrm{~mm})$ & $0.61 \mathrm{~m} ; 16 \mathrm{~mm}$ \\
\hline Pile bending stiffness, El & $263 \mathrm{MNm}^{2}$ \\
\hline Pile length & $\begin{array}{l}3.5 \mathrm{~m} \text { and } 7.0 \mathrm{~m} \text { (STC), } 6.7 \mathrm{~m} \text { and } 13.4 \mathrm{~m} \text { (XL-TTC): these correspond to the OLEMI } \\
\text { calculated depth and two times the OLEMI calculated depth for the specified pile loading }\end{array}$ \\
\hline Contact wire height above pile top & $5.5 \mathrm{~m}$ \\
\hline Ineffective soil depth & $1.5 \times$ pile diameter, $d$ \\
\hline Soil strength, $\phi^{\prime}$ & $30^{\circ}$ \\
\hline Soil Young's modulus, E': kPa & $\begin{array}{l}\text { 15, } 30 \text { and } 60 \mathrm{MPa} \text { : these correspond to one, two and four times the value of } \\
15 \mathrm{MPa} \text { used by Krechowiecki-Shaw and Alobaidi (2015) }\end{array}$ \\
\hline $\begin{array}{l}\text { Limiting lateral soil stress below ineffective } \\
\text { depth }\end{array}$ & $3 K_{p} \times$ vertical effective stress at the same depth \\
\hline Soil unit weight, $\gamma$ & $18 \mathrm{kN} / \mathrm{m}^{3}$ \\
\hline Pore water pressures & Hydrostatic below a water table at ground level \\
\hline
\end{tabular}

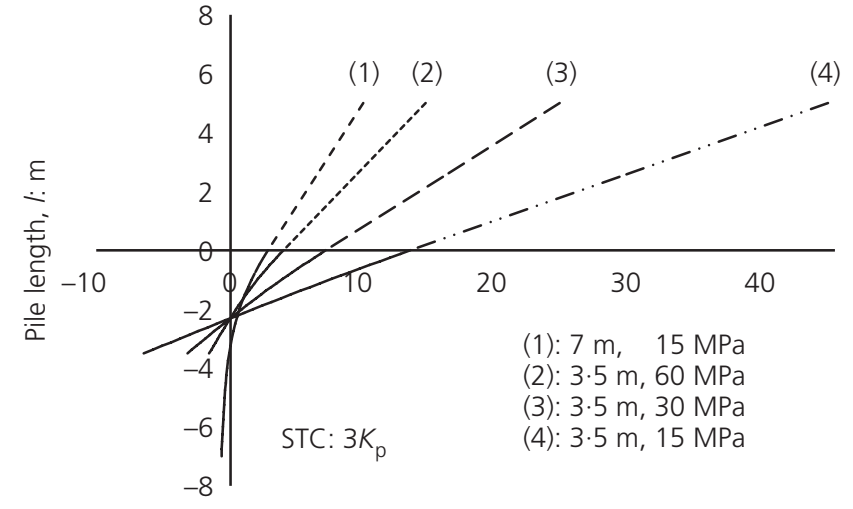

Deflection: $\mathrm{mm}$

Figure 17. Calculated pile deflections using ALP analysis - STC. Pile lengths and soil stiffnesses as indicated. Limiting lateral earth pressure coefficient $=9\left(=3 K_{\mathrm{p}} ; \phi^{\prime}=30^{\circ}\right.$ and $\left.\delta=0\right)$

assumed soil stiffness. This is unsurprising, as the $3.5 \mathrm{~m}$ pile is effectively 'short', so that the mode of deformation is essentially by rotation about a pivot point near the toe. Doubling the length to $7 \mathrm{~m}$ changes the pile behaviour from 'short' to 'long' and the mode of deformation from rigid body rotation to bending with the bottom end effectively fixed. This brings a significant reduction in the calculated wire height deflection.

- For the XL-TTC, the calculated wire height deflection is relatively insensitive to changes in soil stiffness and an increase in the pile length. This is because the pile is already 'long', with its lower end largely fixed.

The effectiveness of the fixity is improved slightly by the increase in soil stiffness from $15 \mathrm{MPa}$ to $30 \mathrm{MPa}$, but deformation is predominantly due to pile bending and the effect of the soil stiffness is small.

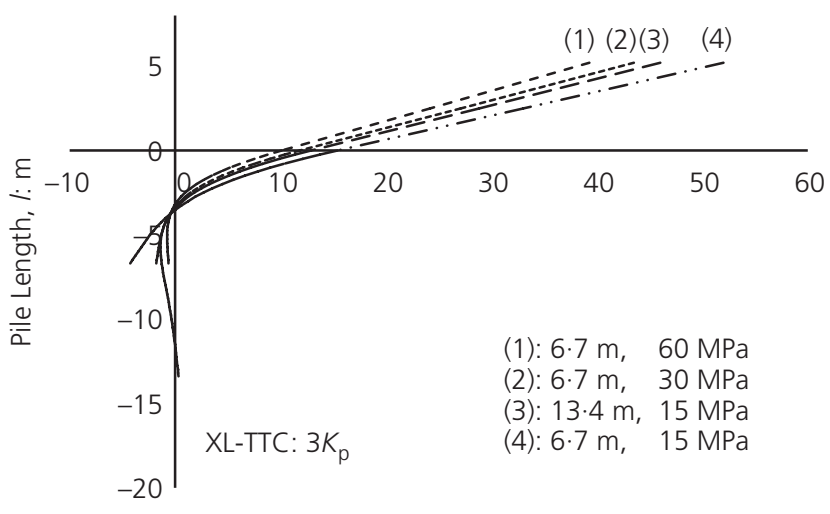

Deflection: $\mathrm{mm}$

Figure 18. Calculated pile deflections using ALP analysis $\mathrm{XL}-\mathrm{TTC}$. Pile lengths and soil stiffnesses as indicated. Limiting lateral earth pressure coefficient $=9\left(=3 K_{\mathrm{p}} ; \phi^{\prime}=30^{\circ}\right.$ and $\left.\delta=0\right)$

Table 9. Summary of calculated wire height deflections

\begin{tabular}{|c|c|c|c|c|}
\hline \multirow{2}{*}{$\begin{array}{l}\text { Structure } \\
\text { type }\end{array}$} & \multirow{2}{*}{$\begin{array}{l}\text { Pile } \\
\text { length: } \mathrm{m}\end{array}$} & \multirow{2}{*}{$\begin{array}{l}\text { Soil Young's } \\
\text { modulus: MPa }\end{array}$} & \multicolumn{2}{|c|}{$\begin{array}{c}\text { Wire height } \\
\text { deflection: } \mathrm{mm}\end{array}$} \\
\hline & & & Total & Variable \\
\hline \multirow[t]{4}{*}{ STC } & $3 \cdot 5$ & 15 & $45 \cdot 7$ & $39 \cdot 1$ \\
\hline & & 30 & $25 \cdot 2$ & $21 \cdot 5$ \\
\hline & & 60 & $15 \cdot 0$ & $12 \cdot 8$ \\
\hline & $7 \cdot 0$ & 15 & $10 \cdot 2$ & 8.7 \\
\hline \multirow[t]{4}{*}{ XL-TTC } & $6 \cdot 7$ & 15 & $52 \cdot 0$ & $29 \cdot 4$ \\
\hline & & 30 & $43 \cdot 4$ & $24 \cdot 6$ \\
\hline & & 60 & $39 \cdot 2$ & $22 \cdot 2$ \\
\hline & $13 \cdot 4$ & 15 & $46 \cdot 0$ & $26 \cdot 0$ \\
\hline
\end{tabular}

For simple structures such as the majority of OLE mast foundations, an attempt to carry out a separate SLS calculation with inappropriate soils parameters is almost certainly 
Table 10. Summary of loading and geometrical parameters and symbols used in the different methods of analysis source documents

\begin{tabular}{|c|c|c|c|}
\hline \multirow[b]{2}{*}{ Description of parameter } & \multicolumn{3}{|c|}{ Symbol(s) used } \\
\hline & $\begin{array}{l}{ }^{\text {a }} \text { This paper (broadly } \\
\text { consistent with Fleming } \\
\text { et al. }(1994,2009))\end{array}$ & BBPCL method & ORE \\
\hline Equivalent lateral load & $H$ & {$[H]$} & $T$ \\
\hline Ineffective depth of soil & $h^{\prime}$ & {$\left[h^{\prime}\right]$} & $h^{\prime}$ \\
\hline $\begin{array}{l}\text { Height of action of lateral } \\
\text { load above effective top } \\
\text { of foundation }\end{array}$ & e & [e] & $H+h^{\prime}$ \\
\hline $\begin{array}{l}\text { Height of action of lateral } \\
\text { load above ground surface }\end{array}$ & $\left(e-h^{\prime}\right)$ & {$\left[\left(e-h^{\prime}\right)\right]$} & $H$ \\
\hline Effective depth of foundation & 1 & $D$ & $\left(h-h^{\prime}\right)$ \\
\hline Foundation plan dimensions & Diameter, $d$ & $\begin{array}{l}\text { Length, } L \text { perpendicular } \\
\text { to the overturning } \\
\text { load }\end{array}$ & $\begin{array}{l}\text { e parallel and } b \text { perpendicular to the overturning } \\
\text { load. } a \text { is the smaller of } e \text { and } b \text {. If the foundation } \\
\text { is } a \text { cylinder of diameter, } D, e=b=a=0.8 D\end{array}$ \\
\hline $\begin{array}{l}\text { Depth from effective top of } \\
\text { foundation to pivot point }\end{array}$ & $z_{p}$ & Assumed equal to $2 D / 3$ & N/A \\
\hline
\end{tabular}

${ }^{a}$ Denotes symbols adopted in comparative calculations

misconceived. Eurocode 7 (BSI, 2013) Clause 2.4.8 (4) does not require an explicit SLS calculation provided

\begin{abstract}
'It may be verified that a sufficiently low fraction of the ground strength is mobilised to keep deformations within the required serviceability limits, provided this simplified approach is restricted to design situations where established comparable experience exists with similar ground, structures and application method.'
\end{abstract}

Achieving this criterion was the original purpose of the 'load factor' - usually applied as a strength factor in geotechnical engineering analysis of laterally loaded piles and retaining walls - in a plasticity-based design (see, e.g. Baker and Heyman, 1969). It is the authors' opinion that for simple embedded retaining walls and laterally loaded piles, the partial factors specified in Eurocode 7 combination 2 as interpreted through the UK National Annex were intended to give results broadly compatible with earlier approaches, whose sufficiency has been demonstrated by many decades of experience of satisfactory structural performance in both stability and serviceability. By comparing the results of ULS calculations to the empirical OLEMI approach, the work described in this paper then justifies the use of Clause 2.4.8(4) for the design of OLE foundations.

\section{Conclusions}

In level or sloping ground, factored LEAs in terms of total stresses, and in terms of effective stresses with zero or hydrostatic pore pressures, give results that are broadly comparable with the OLEMI method in terms of the required pile embedment depth, for a variety of soil strengths.

(a) The fact that the limit equilibrium ULS analyses give broadly similar results and are sometimes more conservative than the proven OLEMI method shows that for these types of structure, the limit equilibrium calculation is very robust.

(b) The OLEMI approach is likely to give shorter piles than the factored limit equilibrium calculation for smaller applied loads (i.e. a STC), soils of lower effective angle of shearing resistance and intermediate slope angles in the range $10-20^{\circ}$. For soil strengths greater than about $30^{\circ}$, higher loads (i.e. a TTC and an XL-TTC), and slope angles less than about $10^{\circ}$ or greater than $20^{\circ}$, the OLEMI method may give slightly longer piles than the factored LEA.

(c) The effect of pore water pressures on the conservatism or otherwise of the OLEMI approach relative to the factored effective stress LEA is negligible.

(d) Undrained LEA, which for transient and short-term loading in clay soils having relatively low angles of effective shearing resistance is likely to be more appropriate than effective stress analysis, gives shorter pile lengths than the OLEMI method for soils having undrained shear strengths greater than $78 \mathrm{kPa}$ for the loads associated with the STC, and greater than $33 \mathrm{kPa}$ for the loads associated with the XL-TTC.

(e) The apparent overdesign of the GWEP foundations appears to have arisen largely because of an attempt to carry out an explicit SLS calculation using overconservative soil stiffnesses, and/or carrying out limit equilibrium ULS calculations that made no allowance for three-dimensional effects.

( $f$ ) The satisfactory performance of a large number of OLEMI-designed foundations provides further evidence that a specific SLS check for this type of relatively simple structure is not required.

(g) The comparative calculations should give designers the confidence to use the OLEMI method, or LEA with the 
Table 11. Other key terms and symbols used in the paper

\begin{tabular}{|c|c|c|}
\hline Term & Definition & Symbol \\
\hline $\begin{array}{l}\text { Effective angle of shearing } \\
\text { resistance, effective } \\
\text { angle of friction }\end{array}$ & $\begin{array}{l}\text { Apparent frictional strength of the soil, defining the } \\
\text { Mohr-Coulomb failure envelope in effective stress } \\
\text { terms, }\left(\tau / \sigma^{\prime}\right)_{\max }=\tan \phi^{\prime} ; \phi^{\prime} \text { might be defined either at } \\
\text { the peak stress ratio } \phi_{\text {peak, }}^{\prime} \text { or at the critical state, } \phi_{\text {crit. }}^{\prime} \\
\text { The strength that needs to be mobilised to maintain a } \\
\text { given equilibrium stress state is denoted } \phi_{\text {mob }}^{\prime}\end{array}$ & $\phi^{\prime}$ \\
\hline Effective soil unit weight & $\begin{array}{l}\text { Weight of a unit volume of soil, adjusted for pore water } \\
\text { pressure (buoyancy) effects, defined such that the } \\
\text { vertical effective stress at depth } z=\gamma^{\star} z-\text { that is } \\
\gamma^{\star}=(\gamma-\mathrm{du} / \mathrm{d} z) \text { at depth } z \text {, where } u \text { is the pore water } \\
\text { pressure }\end{array}$ & $\begin{array}{l}\gamma^{*}=(\gamma-\mathrm{d} u / \mathrm{d} z) \text { at depth } z, \text { where } u \text { is the pore water } \\
\text { pressure. UIC-ORE (1957) uses the symbol } \Delta \\
\text { (although it assumes that the soil is not } \\
\text { waterlogged, so that } u=0 \text {, and there is some } \\
\text { ambiguity about the dimensions of } \Delta) \text {, and Fleming } \\
\text { et al. (1994) use } \gamma^{\prime}\end{array}$ \\
\hline
\end{tabular}

partial factors specified in Eurocode 7. This should result in shorter pile lengths that will perform adequately, helping to reduce electrification costs back towards historic levels.

\section{Acknowledgements}

The work described in this paper was funded and carried out under the Network Rail - University of Southampton Strategic Partnership in Future Infrastructure Systems. The authors are grateful to colleagues including Dr Anthony Blake, Dr Tony Lock and Rob Stacey for their discussions, insights and help with various parts of the paper, and to Dr Joel Smethurst for carrying out the ALP analyses.

\section{Appendix}

\section{A1.1 Symbols and nomenclature}

The key geometrical parameters and symbols used in the source documents for each method are summarised in Table 10. Symbols given in square brackets [] do not feature in the source document but are shown for completeness and/or overall clarity.

Other key terms and symbols are defined in Tables 11 and 12.

\section{A1.2 OLEMI and allocation design methodology}

It was stated in the main text that the OLEMI method gives foundations that are approximately 10 to $20 \%$ longer than those determined using the UIC-ORE design method as a result of simply neglecting the vertical loads $(\mathrm{Nr}$ in Equations 2 and 4). All other corrections for topographical features and foundation type are the same in both methods.

The updated Network Rail specification for the design and installation of overhead line foundations (NR/L2/CIV/074 (Network Rail, 2017)) uses the UK Master Series (Network Rail, 2015c) foundation allocation method derived from OLEMI (i.e. no vertical load is considered).

A series of 'strength depth' tables for allocating concrete 'grabbed' (i.e. excavated and cast-in-place) side-bearing
Table 12. Summary of loading and geometrical parameters and symbols used

\begin{tabular}{lc}
\hline Parameter & Symbol \\
\hline $\begin{array}{l}\text { Resultant lateral load (wind plus or minus component of } \\
\text { wire tension) }\end{array}$ & $H$ \\
Height of action of resultant lateral load above ground & $y$ \\
$\quad$ level & \\
Weight of mast & $W_{\mathrm{M}}$ \\
Weight of foundation & $W_{\mathrm{F}}$ \\
Weight of boom and OLE supported & $W$ \\
Horizontal distance of line of action of $w$ from centre of & $x$ \\
$\quad$ foundation & $h^{\prime}$ \\
Disturbed or unconsolidated depth of soil & $M_{\mathrm{ult}}$ \\
Ultimate moment of resistance at ground level & $M_{\mathrm{GL}}$ \\
Design moment at ground level & $M_{\mathrm{SB}}$ \\
Design moment at the stanchion base & $h$ \\
Total depth of foundation & $d$ \\
Foundation diameter &
\end{tabular}

foundations (parallelepiped) and augured tubular steel pile foundations are provided in drawing $\mathrm{MS} / \mathrm{B} 80 / \mathrm{L} 00 / \mathrm{A} 3$. These tables provide the foundation lengths in increments of $0.1 \mathrm{~m}$ and the corresponding level ground moment based on a noneffective near-surface depth $h^{\prime}=0.3 \mathrm{~m}$ and a soil effective unit weight $\gamma^{*}=15 \mathrm{kN} / \mathrm{m}^{3}$. For grabbed side-bearing foundations a towards-track moment - that is level terrain factor $K=1 \cdot 3$ - is used to calculate the foundation 'strength depth' $(D)$. For the tubular steel pile foundations, an away-from-track moment (i.e. level terrain factor $K=1$ ) is used, resulting in increased foundation 'strength depths' for a given level ground moment. This apparent discrepancy accommodates the likely ground disturbance in pre-auguring the ground to facilitate tubular steel pile (CHS) installation. 'Augured' is a term used only in the title of drawing MS/B98/K08/A3 (Table 13).

To facilitate foundation allocation according to in-service foundation type, terrain condition and loading direction, two allocation schedules for grabbed and hand excavated (parallelepiped) and augured side-bearing (tubular steel) foundations are provided in drawings MS/B98/K05/A3 and MS/B98/K08/A3, respectively. These allocation schedules introduce a modification 
Table 13. Supporting drawings NR/L2/CIV/074

\begin{tabular}{|c|c|c|}
\hline Drg no. & Title & Purpose \\
\hline MS/B98/K05/A3 & $\begin{array}{l}\text { Foundation allocation schedule: grabbed and } \\
\text { hand-excavated side-bearing foundations }\end{array}$ & $\begin{array}{l}\text { To determine topographical 'location conditions' that will affect moment } \\
\text { capacity and design depth }\end{array}$ \\
\hline MS/B98/K08/A3 & $\begin{array}{l}\text { Foundation allocation schedule: augured side- } \\
\text { bearing foundations }\end{array}$ & $\begin{array}{l}\text { To determine topographical 'location conditions' that will affect moment } \\
\text { capacity and design depth }\end{array}$ \\
\hline MS/B80/K73/A3 & $900 \mathrm{~mm}$ dia. augured side-bearing foundation & $800 \mathrm{~mm}$ dia. augured concrete foundations \\
\hline MS/B80/L00/A3 & $\begin{array}{l}\text { Strength depth table for different OLE } \\
\text { foundation types - based on ORE-UIC } \\
\text { method }\end{array}$ & $\begin{array}{l}\text { Strength depth tables for (a) } 540 \times 580 \mathrm{~mm} \text { and } 800 \times 800 \mathrm{~mm} \text { concrete } \\
\text { grabbed side-bearing foundations; (b) } 610 \text { and } 762 \mathrm{~mm} \text { dia. tubular } \\
\text { steel piles }\end{array}$ \\
\hline MS/B98/K04/A4 & Allocation method of bearing foundations & $\begin{array}{l}\text { Details allocation method. Defines minimum overturning moment at } \\
\text { ground level }\end{array}$ \\
\hline
\end{tabular}

Table 14. Foundation allocation schedule for grabbed and side-bearing foundations

\begin{tabular}{|c|c|c|c|c|c|}
\hline Location & $\begin{array}{l}\text { Direction of } \\
\text { moment }\end{array}$ & $\begin{array}{l}\text { Factor } \\
\quad F\end{array}$ & $\begin{array}{l}\text { Acceptable } \\
\text { conditions }\end{array}$ & Corrections & Sketch \\
\hline Side of cutting & $\begin{array}{l}\text { Uphill } \\
\text { Downhill }\end{array}$ & $\begin{array}{l}1.37 \\
1.53\end{array}$ & All with corrections & Add 0.9 to $h$ & \\
\hline Side of embankment & $\begin{array}{l}\text { Uphill } \\
\text { Downhill }\end{array}$ & $\begin{array}{l}1.37 \\
1.53\end{array}$ & All with corrections & Add 0.9 to $h$ & \\
\hline Top of cutting & $\begin{array}{l}\text { Uphill } \\
\text { Downhill }\end{array}$ & $\begin{array}{l}1.37 \\
1.53\end{array}$ & $\begin{array}{l}0.9 \leq a \leq h \\
0.9 \leq a \leq 0.7 h\end{array}$ & $\begin{array}{l}\text { If } a<0.9 \text { : Add }(0.9-a) \text { to } h \\
\text { If } a>h \text { : regard as level ground } \\
\text { If } a<0.9 \text { : Add }(0.9-a) \text { to } h \\
\text { If } a>0.7 h \text { : regard as level ground }\end{array}$ & \\
\hline Top of embankment & $\begin{array}{l}\text { Uphill } \\
\text { Downhill }\end{array}$ & $\begin{array}{l}1 \cdot 37 \\
1.53\end{array}$ & $\begin{array}{l}0.9 \leq a \leq h \\
0.9 \leq a \leq 0.7 h\end{array}$ & $\begin{array}{l}\text { If } a<0.9 \text { : Add }(0.9-a) \text { to } h \\
\text { If } a>h \text { : regard as level ground } \\
\text { If } a<0.9 \text { : Add }(0.9-a) \text { to } h \\
\text { If } a>0.7 h \text { : regard as level ground }\end{array}$ & \\
\hline Level ground & $\begin{array}{l}\text { Away from track } \\
\text { Towards track }\end{array}$ & $\begin{array}{l}1 \cdot 3 \\
1 \cdot 0\end{array}$ & $\begin{array}{l}a \geq h \\
a \geq 0 \cdot 7 h\end{array}$ & $\begin{array}{l}\text { If } a<h \text { : regard as side of } \\
\text { embankment } \\
\text { If } a<0 \cdot 7 \mathrm{H} \text { : regard as side of } \\
\text { embankment }\end{array}$ & \\
\hline Base of embankment & $\begin{array}{l}\text { Uphill } \\
\text { Downhill }\end{array}$ & $\begin{array}{l}1.0 \\
1.3\end{array}$ & $\begin{array}{l}a \geq 0 \cdot 7 h \\
a \geq h\end{array}$ & $\begin{array}{l}\text { If } a<0 \cdot 7 \mathrm{H} \text { : regard as side of } \\
\text { embankment } \\
\text { If } a<h \text { : regard as side of } \\
\text { embankment }\end{array}$ & \\
\hline $\begin{array}{l}\text { Base of cutting } \\
\text { slope }>20^{\circ}\end{array}$ & $\begin{array}{l}\text { Uphill } \\
\text { Downhill }\end{array}$ & $\begin{array}{l}1 \cdot 3 \\
1 \cdot 0\end{array}$ & $\begin{array}{l}a \geq 0.9 \\
a \geq 0.9\end{array}$ & $\begin{array}{l}\text { If } a<0.9 \text { : Add }(0.9-a) \text { to } h \\
\text { If } a<0.9 \text { : Add }(0.9-a) \text { to } h\end{array}$ & \\
\hline $\begin{array}{l}\text { Base of cutting } \\
\text { slope } \leq 20^{\circ}\end{array}$ & Uphill & 0.867 & $\begin{array}{l}a \geq 0 \cdot 7 h \\
a \geq h\end{array}$ & $\begin{array}{l}\text { If } a<0 \cdot 7 h \text { : regard as base of } \\
\text { cutting }>20^{\circ} \\
\text { If } a<h \text { : regard as base of } \\
\text { cutting }>20^{\circ}\end{array}$ & \\
\hline
\end{tabular}

Note: $T_{\mathrm{G}}$ is the lowest ground level in contact with foundation. All units of correction to $a$ and $h$ are in metres

factor $F$ that converts the level ground moment to an equivalent level ground moment that reflects the actual direction of loading and terrain type. This equivalent level ground moment and its corresponding foundation 'strength depth' is derived from the appropriate table in drawing MS/B80/L00/A3. The additional corrections to foundation length based on slope angle, direction of loading, proximity to topographical features related to foundation type are also depicted in MS/B98/K05/A3 and MS/B98/K08/A3 and are in accordance with UIC-ORE rules. These are replicated in Tables 14 and 15, respectively.
Table 16 shows that the application of the factor $F$ values provided in Table 14 (MS/B98/K05/A3: grabbed) converts the across-track level ground moment to the appropriate ORE $K$ factor for each terrain type and loading direction as presented in Table 2. The factor $F$ values provided in Table 15 (MS/B98/K08/A3: augured) are identical, but because the 'strength depth' table in MS/B80/L00/A3 has been derived using a $K=1$ (away-from-track moment), the equivalent ORE $K$ factor is reduced, resulting in foundation lengths approximately $17 \%$ and $23 \%$ longer for $0.610 \mathrm{~m}$ and $0.762 \mathrm{~m} \mathrm{CHS}$ foundations, respectively. 
Table 15. Foundation allocation schedule augured side-bearing foundations

\begin{tabular}{|c|c|c|c|c|c|}
\hline Location & $\begin{array}{l}\text { Direction of } \\
\text { moment }\end{array}$ & $\begin{array}{l}\text { Factor } \\
F\end{array}$ & $\begin{array}{l}\text { Acceptable } \\
\text { conditions }\end{array}$ & Corrections & Sketch \\
\hline Side of cutting & $\begin{array}{l}\text { Uphill } \\
\text { Downhill }\end{array}$ & $\begin{array}{l}1 \cdot 37 \\
1.53\end{array}$ & All with corrections & Add 0.6 to $h$ & \\
\hline Side of embankment & $\begin{array}{l}\text { Uphill } \\
\text { Downhill }\end{array}$ & $\begin{array}{l}1.37 \\
1.53\end{array}$ & All with corrections & Add 0.6 to $h$ & \\
\hline \multirow[t]{2}{*}{ Top of cutting } & Uphill & $1 \cdot 37$ & $0 \cdot 9 \leq a \leq h$ & \multirow{2}{*}{$\begin{array}{l}\text { If } a<0 \cdot 6 \text { : Add }(0 \cdot 6-a) \text { to } h \\
\text { If } a>h \text { : regard as level ground } \\
\text { If } a<0 \cdot 6: \text { Add }(0 \cdot 6-a) \text { to } h \\
\text { If } a>0 \cdot 7 h \text { : regard as level ground }\end{array}$} & \\
\hline & Downhill & 1.53 & $0.9 \leq a \leq 0.7 h$ & & \\
\hline \multirow[t]{2}{*}{ Top of embankment } & Uphill & $1 \cdot 37$ & $0.9 \leq a \leq h$ & $\begin{array}{l}\text { If } a<0.6 \text { : Add }(0.6-a) \text { to } h \\
\text { If } a>h \text { : regard as level ground }\end{array}$ & \\
\hline & Downhill & $1 \cdot 53$ & $0.9 \leq a \leq 0.7 h$ & $\begin{array}{l}\text { If } a<0.6 \text { : Add }(0.6-a) \text { to } h \\
\text { If } a>0.7 h \text { : regard as level ground }\end{array}$ & \\
\hline \multirow[t]{2}{*}{ Level ground } & Away from track & $1 \cdot 3$ & $a \geq h$ & $\begin{array}{l}\text { If } a<h \text { : regard as side of } \\
\text { embankment }\end{array}$ & \multirow{2}{*}{ Ditch } \\
\hline & Towards track & $1 \cdot 0$ & $a \geq 0 \cdot 7 h$ & $\begin{array}{l}\text { If } a<0.7 \mathrm{H} \text { : regard as side of } \\
\text { embankment }\end{array}$ & \\
\hline \multirow[t]{2}{*}{ Base of embankment } & Uphill & $1 \cdot 0$ & $a \geq 0 \cdot 7 h$ & $\begin{array}{l}\text { If } a<0.7 \mathrm{H} \text { : regard as side of } \\
\text { embankment }\end{array}$ & \multirow{2}{*}{ Ditch } \\
\hline & Downhill & $1 \cdot 3$ & $a \geq h$ & $\begin{array}{l}\text { If } a<h \text { : regard as side of } \\
\text { embankment }\end{array}$ & \\
\hline \multirow{2}{*}{$\begin{array}{l}\text { Base of cutting } \\
\text { slope }>20^{\circ}\end{array}$} & Uphill & $1 \cdot 3$ & $a \geq 0.9$ & \multirow{2}{*}{$\begin{array}{l}\text { If } a<0.6 \text { : Add }(0.6-a) \text { to } h \\
\text { If } a<0.6 \text { : Add }(0.6-a) \text { to } h\end{array}$} & \\
\hline & Downhill & $1 \cdot 0$ & $a \geq 0 \cdot 9$ & & \\
\hline \multirow[t]{2}{*}{$\begin{array}{l}\text { Base of cutting } \\
\text { slope } \leq 20^{\circ}\end{array}$} & Uphill & 0.867 & $a \geq 0.7 h$ & \multirow{2}{*}{$\begin{array}{l}\text { If } a<0 \cdot 7 h \text { : regard as base of } \\
\text { cutting }>20^{\circ} \\
\text { If } a<h \text { : regard as base of } \\
\text { cutting }>20^{\circ}\end{array}$} & \\
\hline & Downhill & 0.722 & $a \geq h$ & & \\
\hline
\end{tabular}

Note: $T_{\mathrm{G}}$ is the lowest ground level in contact with foundation. All units of correction to $a$ and $h$ are in metres

Drawing MS/B98/K04/A3 provides minimum overturning moments for STC and TTC structures. These have been derived from the capacity of the OLE stanchion - the ' $3 / 4$ mast strength'. These values are currently the subject of further investigation.

\section{A1.3 Use of the lateral pile/soil interaction program ALP to illustrate the effect of the assumed soil stiffness on calculated wire height deflections}

To investigate the influence of foundation pile length and assumed soil stiffness on this potential SLS, the deflection at wire height was estimated using the Oasys program ALP (analysis of laterally loaded piles).

ALP uses rudimentary soil-structure interaction to calculate the deflected pile shape (lateral displacement and rotation), shear forces and bending moments and lateral soil pressures, in response to the application of loads or the imposition of soil displacements. The soil is represented by non-linear springs and the pile as elastic beam elements. The program is limited to laterally loaded piles in level ground. Load-deflection behaviour is modelled either by assuming elastic-plastic soil behaviour or by specifying load-deflection $(P-y)$ curves: in the
Table 16. Factor $F$ and equivalent ORE $K$ factor (refer to Table 2)

\begin{tabular}{lll} 
& \multicolumn{2}{c}{ ORE $\boldsymbol{K}$ factors } \\
\cline { 2 - 3 } Factor $\boldsymbol{F}$ & Grabbed & Augured \\
\hline $1 \cdot 53$ & $1 \cdot 3 / 1 \cdot 53=0 \cdot 85$ & $1 / 1 \cdot 53=0 \cdot 65$ \\
$1 \cdot 37$ & $1 \cdot 3 / 1 \cdot 37=0 \cdot 85$ & $1 / 1 \cdot 37=0 \cdot 73$ \\
$1 \cdot 3$ & $1 \cdot 3 / 1 \cdot 3=1$ & $1 / 1 \cdot 3=0 \cdot 77$ \\
$1 \cdot 0$ & $1 \cdot 3 / 1=1 \cdot 3$ & $1 / 1=1$ \\
0.867 & $1 \cdot 3 / 0 \cdot 867=1 \cdot 5$ & $1 / 0 \cdot 867=1 \cdot 15$ \\
0.722 & $1 \cdot 3 / 0 \cdot 722=1 \cdot 8$ & $1 / 0 \cdot 722=1 \cdot 38$ \\
\end{tabular}

current analyses, the former approach was adopted. Analyses are very quick to undertake as only two stiffness matrices are developed, representing the pile in bending and the soil stiffness.

In the current analyses, soil stiffnesses were taken as integer multiples $(\times 1, \times 2$ and $\times 4)$ of the value of $15 \mathrm{MPa}$ used by Krechowiecki-Shaw and Alobaidi (2015).

The lateral displacement at contact wire height (assumed to be $5 \cdot 2 \mathrm{~m}$ above ground level) was determined by multiplying the calculated rotation of the top of the pile by the distance from the effective top of the pile to the contact wire $(5.5 \mathrm{~m})$, and 
adding this to the calculated lateral displacement of the effective top of the pile.

\section{REFERENCES}

AMEC SPIE Rail (2000) Channel Tunnel Rail Link; Calculation Note for Cylindrical Foundation, Document No. 570-CM-SAMSP11202-AB, Revision AB, July 2000. AMEC SPIE Rail, Croydon, UK.

Baker JF and Heyman J (1969) Plastic Design of Frames: 1. Fundamentals. Cambridge University Press, Cambridge, UK. Barton YO (1982) Laterally Loaded Model Piles in Sand. $\mathrm{PhD}$ dissertation, University of Cambridge, Cambridge, UK.

BBPCL (Balfour Beatty Power Construction Ltd) (1990) Foundation Design Manual, Issue 1, 15 May 1990. BBPCL, London, UK. See https:// doi.org/10.5258/SOTON/D1117 (accessed 02/12/2019).

Bowles JE (1996) Foundation Analysis and Design, 5th edn. McGraw-Hill, New York, NY, USA.

Brinch Hansen J (1961) A Revised and Extended Formula for Bearing Capacity. Danish Geotechnical Institute, Copenhagen, Denmark, Bulletin No. 12.

Broms BB (1964a) Lateral resistance of piles in cohesive soils. Journal of the Soil Mechanics and Foundations Division 90(SM2): 27-63.

Broms BB (1964b) Lateral resistance of piles in cohesionless soils. Journal of the Soil Mechanics and Foundations Division 90(SM3): $123-156$.

BSI (2013) Eurocode 7: Geotechnical Design Part 1: General Rules. BE EN 1997-1: 2004+A1:2013. BSI, London, UK.

Buro Happold (Buro Happold Engineering) (2015a) NR-Working Groups for Electrification Standards Typical Loading for GW Series 1 TTC, 033622-BH (006/010), January/February 2015. Buro Happold. See https://doi.org/10.5258/SOTON/D1117 (accessed 02/12/2019).

Buro Happold (2015b) Series 1 Standard STC and TTC rev02, 033677, September 2015. Buro Happold. See https://doi.org/10.5258/ SOTON/D1117 (accessed 02/12/2019).

Buro Happold (2015c) Series 1 Critical Loading States for XL-TTC Structures, 003677-BHP-DN-XL-TTC-001, October 2015. Buro Happold. See https://doi.org/10.5258/SOTON/D1117 (accessed 02/12/2019).

Duley A (2019) Soil Parameters for Modelling Critical Velocity Effects of Railways. University of Southampton $\mathrm{PhD}$ dissertation, June, 2019, Southampton, UK.

Fleming WGK, Weltman AJ, Randolph MF and Elson WK (1994) Piling Engineering, 2nd edn. Blackie and Son, Bishopbriggs, UK

Fleming WGK, Weltman AJ, Randolph MF and Elson WK (2009) Piling Engineering, 3rd edn. Taylor \& Francis, London, UK.

Georgiadis K and Georgiadis M (2010) Undrained lateral pile response in sloping ground. ASCE Journal of Geotechnical and Geoenvironmental Engineering 136(11): 1489-1500.

Kanagasabai S, Smethurst JA and Powrie W (2011) Three-dimensional numerical modelling of discrete piles used to stabilize landfills. Canadian Geotechnical Journal 48: 1393-1411, https://doi.org/ 10.1139/T11-046.

Krechowiecki-Shaw CJ and Alobaidi IM (2015) An interaction chart design method for Eurocode compliant railway electrification mast foundations. Construction and Building Materials 92: 104-110.

Mootoosamy VKS, Wiles G and Holder S (2015) Network Rail's In-Service Experience of the ORE Method, 133956-IED-REPEOH-000222, 12 June 2015. See https://doi.org/10.5258/SOTON/ D1117 (accessed 02/12/2019)

NAO (National Audit Office) (2016) Modernising the Great Western Railway. Department for Transport and Network Rail, London, UK, Report no. HC 781.
Nimityongskul N, Kawamata Y, Rayamajhi D and Ashford SA (2018) Ful scale tests on effects of slope on lateral capacity of piles installed in cohesive ground. ASCE Journal of Geotechnical and Geoenvironmental Engineering 144(1): 04017103.

Network Rail (2004) Instruction for the Design of Overhead Line Structures. Network Rail, London, UK, NR/SP/ELP/27215.

Network Rail (2015a) Network Rail's UK Masters Series: Strength Depth Table for Different OLE Foundation Types - Based on ORE-UIC Method, June 2015. Network Rail, London, UK, $\mathrm{MS} / \mathrm{B} 80 / \mathrm{L} 00 / \mathrm{A} 3$.

Network Rail (2015b) Wind Loading of OLE Structures. Network Rail, London, UK, NR/L2/CIV/072.

Network Rail (2015c) Design of Overhead Line Structures. Network Rail, London, UK, NR/L2/CIV/073.

Network Rail (2017) Design and Installation of Overhead Line Foundations. Network Rail, London, UK, NR/L2/CIV/074.

Oasys (Oasys Ltd) (2017) ALP 19.3 Help Guide. Oasys, London, UK.

Pan D (2013) Numerical Modelling of Rows of Discrete Piles Used to Stabilise Landslides Under Long-Term Conditions in Clays. $\mathrm{PhD}$ dissertation, University of Southampton, Southampton, UK.

Pan D, Smethurst JA and Powrie W (2012) Limiting pressure on a laterally loaded pile in frictional soil. Géotechnique Letters 2(2): 55-60, https://doi.org/10.1680/geolett.12.00007.

Powrie W (2014) Soil Mechanics: Concepts and Applications, 3rd edn. Taylor \& Francis, London, UK.

Ramelot C and van Deperre L (1950) Les foundations de Pylons Electriques: Leur Resistance au reveresement, leur stabilite, leur calcul etude experimentale. Comptes Rendus des Recherches de la Recherche Scientifique dans l'Industrie et Agriculture 2 (in French).

Randolph MF and Houlsby GT (1984) The limiting pressure on a circular pile loaded laterally in cohesive soil. Géotechnique 34(4): 613-623, https://doi.org/10.1680/geot.1984.34.4.613.

RIA (Railway Industry Association) (2019) Electrification Cost Challenge. RIA, London, UK. See https://www.riagb.org.uk/RIA/ Newsroom/Stories/Electrification_Cost_Challenge_Report.aspx and https://doi.org/10.5258/SOTON/D1117 (accessed 02/12/2019).

Sulzberger G (1945) Die fundamente der freileitunstrag werke und ihre berechnung (the foundations of overhead line supports and their calculation). Bulletin SEV 36(1945): 289-307 (in German).

UIC-ORE (International Union of Railways - Office for Research and Experiments) (1957) Calculation of Catenary Masts and Foundations, Interim Report No. 1. International Union of Railways Office for Research and Experiments, Utrecht, the Netherlands.

\section{How can you contribute?}

To discuss this paper, please email up to 500 words to the editor at journals@ice.org.uk. Your contribution will be forwarded to the author(s) for a reply and, if considered appropriate by the editorial board, it will be published as discussion in a future issue of the journal.

Proceedings journals rely entirely on contributions from the civil engineering profession (and allied disciplines). Information about how to submit your paper online is available at www.icevirtuallibrary.com/page/authors where you will also find detailed author guidelines. 